ISSN: 0514-7336

DOI: http://dx.doi.org/10.14201/zephyrus201474117141

\title{
LOS MOLDES DE FUNDICIÓN DE BRONCE PARA HACHAS DE TALÓN DE LA MACOLLA (LINARES DE RIOFRÍO, SALAMANCA). NUEVOS DATOS SOBRE VIEJOS HALLAZGOS
}

\section{The bronze moulds for palstaves from La Macolla (Linares de Riofrio, Salamanca). New data on old findings}

\author{
Óscar García-Vuelta*, Fabián Cuesta-Gómez**, Eduardo Galán Domingo*** e Ignacio Montero-Ruiz* \\ * Instituto de Historia. CCHS-CSIC. C/ Albasanz, 26-28. 28037 Madrid. Correo-e: oscar.gvuelta@cchs.csic.es; igna- \\ cio.montero@cchs.csic.es \\ ** Dpto. de Prehistoria, H. a Antigua y Arqueología. Facultad de Geografía e Historia. C/ Cervantes, s/n. 37002 \\ Salamanca. Correo-e: jfabian.cuestag@usal.es \\ *** Museo Arqueológico Nacional. C/ Serrano, 13. 28001 Madrid. Correo-e: eduardo.galan@mecd.es
}

Recepción: 5/11/2013; Revisión: 26/02/2014; Aceptación: 24/03/2014

BIBLID [0514-7336 (2014) LXXIV, julio-diciembre; 117-141]

\begin{abstract}
Resumen: El hallazgo de dos moldes metálicos para la fundición de hachas de talón con dos anillas en Linares de Riofrío (Salamanca) constituye uno de los más interesantes testimonios conocidos para el estudio de la metalurgia del Bronce Final en la Meseta Norte. Presentamos los resultados de la necesaria revisión documental, formal y arqueométrica de este conjunto. La información obtenida resuelve una parte importante de los problemas derivados de la dispersión de las piezas, que había dificultado su adecuado estudio. El estudio formal de los moldes y la obtención de datos, por vez primera, mediante técnicas arqueométricas (XRF, PIXE) contribuyen a la caracterización tecnológica de la producción y uso de este tipo de objetos.

Los moldes salmantinos se corresponden con el tipo de hachas de talón más frecuente en la Meseta Norte, aunque algunos detalles tipológicos permiten trazar un vínculo con la metalurgia de la región centro de Portugal. Este aspecto, junto con el contexto del hallazgo, ofrece un nuevo punto de interés en el análisis de los procesos tecnológicos e ideológicos del conjunto, aportando nuevos datos para el estudio del reducido grupo de moldes metálicos de este período conocidos en la península Ibérica.

Palabras clave: Bronce Final; Arqueometalurgia; Tecnología; Hachas de talón; Moldes metálicos; Península Ibérica; Meseta Norte española; César Morán.

Aвstract: The discovery of two metal moulds for casting palstaves with two loops in Linares de Riofrío (Salamanca) is one of the most interesting evidences known for the study of the Late Bronze Age metallurgy in the Northern Spanish Plateau. This paper presents the results of a new documentary, formal, and archaeometric review of this finding. Our study was able to resolve most of the problems driven from the moulds early dispersion, which had been hindering their proper analysis. The formal study and archaeometric analysis (XRF, PIXE) of the moulds allowed us to make a complete characterization of the technology behind their casting, as well as their usage.

Although the moulds from La Macolla share features with the palstaves commonly found in the Northern Spanish Plateau, some of their typological details allow us to link them with the Late Bronze Age metallurgy from central Portugal. This aspect, along with the supposed context of the find, is extremely relevant in the analysis of the technological and ideological processes behind these objects, offering new data for the study of the limited group of metal moulds known for this period in the Iberian Peninsula.

Key words: Late Bronze Age; Archaeometallurgy; Technology; Palstaves; Metallic moulds; Iberian Peninsula; Northern Spanish Plateau (Meseta); César Morán.
\end{abstract}




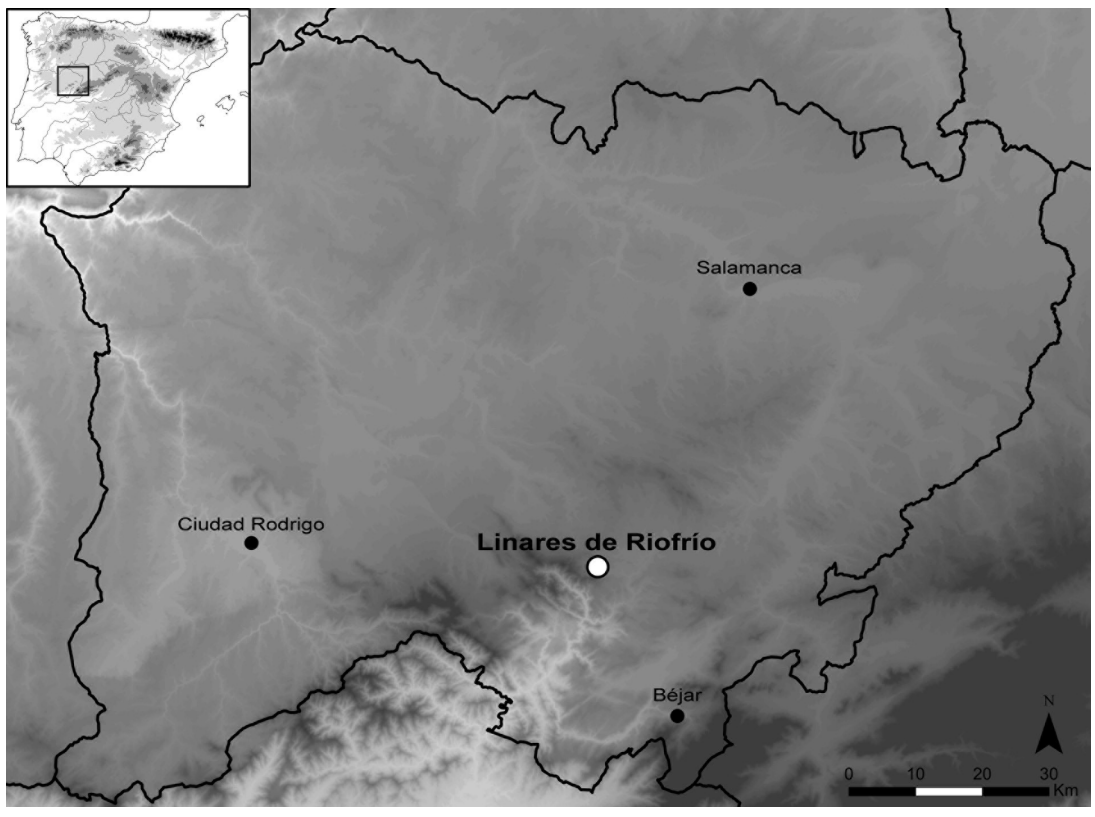

Fig. 1. Mapa de localización del hallazgo en la Peninsula Ibérica.

el Museo Arqueológico Nacional (MAN); la segunda (Fig. 2, dcha.) se conserva desde 1935 en el Instituto Valencia de Don Juan (IVDJ) de Madrid².

Morán dio a conocer este conjunto en varios trabajos publicados entre finales de los años 30 y mediados de los 40 del s. xx, aportando la mayoría de los datos disponibles sobre su contexto (Morán, 1938: 112; 1941; 1942: 148 y ss.). Lamentablemente, el desconocimiento de los avatares sufridos por el conjunto y la ausencia de un estudio directo de los objetos dificultaron su investigación posterior, dando lugar a datos confusos o inexactos que necesitan ser revisados.

En este trabajo presentamos el estudio, por vez primera, de

\section{Introducción}

La investigación sobre las evidencias metalúrgicas del Bronce Final en la Meseta Norte ha experimentado un avance significativo en las dos últimas décadas, gracias a estudios generales o a la publicación de nuevos materiales (p. ej. Fernández Manzano, 1986; Delibes et al., 1999; Fernández Manzano et al., 2005 o Herrán, 2008). Sin embargo, la falta de datos documentales y arqueométricos constituye todavía un importante factor limitador.

En este sentido, presentamos aquí los resultados del estudio documental, formal y arqueométrico realizado sobre un hallazgo que, por su situación geográfica y su singularidad en el contexto peninsular, ofrece un especial interés. Se trata de dos valvas de bronce pertenecientes a otros tantos moldes para la fundición de hachas de talón con anillas, descubiertos en el paraje conocido como La Macolla, en Linares de Riofrío, al s de la provincia de Salamanca (Fig. 1).

El hallazgo de estos moldes se produjo de forma casual en un momento anterior a mediados de 1935, dispersándose tras su aparición. Una valva (Fig. 2, izq.) fue adquirida por el investigador y sacerdote César Morán Bardón ${ }^{1}$, e ingresó posteriormente en

1 Sobre la figura de César Morán véase, entre otros: Gozalbes, 2009. las dos piezas del conjunto, con un triple objetivo: en primer lugar, contribuir a aclarar en lo posible la controversia documental aún existente sobre el hallazgo; en segundo lugar, aportar una revisión formal y arqueométrica actualizada; y, finalmente, encuadrar el hallazgo salmantino en el marco actual de investigación de un tipo de herramienta metalúrgica que, por sus problemas de estudio y escasa representación en la Península Ibérica, carece hasta la fecha de un análisis pormenorizado ${ }^{3}$.

2 Queremos agradecer al Archivo documental del Museo Arqueológico Nacional, al Instituto Valencia de Don Juan y al Museo de Salamanca las facilidades prestadas para el estudio de los materiales y archivos relacionados con este hallazgo.

${ }^{3}$ El estudio de estos materiales se desarrolló inicialmente en los proyectos: Caracterización tecnológica de la metalurgia del Bronce Final en la Península Ibérica (МСут, ВНА 2001-0248); Metales prehistóricos en el Instituto Valencia de Don Juan (CM 06/0112/2003), y Calibración y Concordancia de análisis PIXE y XRF para el estudio de metales antiguos (CM 06/0154/2002). Posteriormente se continuó en los programas Tecnologías para la conservación y revalorización del Patrimonio Cultural (CONSOLIDER-INGENIO 20IO, CSD2007-00058) y El patrimonio arqueológico y documental de la Comunidad Autónoma de Madrid: Sistematización, gestión, puesta en valor y difusión desde el ámbito local al marco europeo (CM S2007/HUM-543). F. Cuesta-Gómez ha disfrutado de una beca de investigación de la Fundación del Patrimonio Histórico de Castilla y León (FPHCyL). 


\section{El hallazgo de La Macolla}

\subsection{Primeras informaciones}

Morán alude por primera vez en 1938 a la aparición de "un molde" de fundición metálico para hachas de la Edad del Bronce en el paraje de La Macolla, sin aportar datos adicionales sobre su hallazgo (1938: 112). Ese mismo año finaliza un trabajo más extenso, en el que precisa que se trata de un conjunto de dos valvas de bronce pertenecientes a moldes diferentes, una de las cuales había logrado adquirir. En dicho estudio, que solo será publicado en 1941, Morán ofrece una somera descripción de los materiales y relata que el hallazgo se habría producido en una peña granítica, cuando unos trabajadores se ocupaban de la extracción de piedra. El autor precisa que esta peña (Fig. 3) albergaría una cubeta, que interpreta como un lagar, y cuyo emplazamiento estaría dentro o en las inmediaciones de un poblado (Morán, 1941: 86) ${ }^{4}$.

Morán no aclaró algunas cuestiones de interés, como la fecha del hallazgo o las circunstancias de adquisición de su molde en la propia localidad de Linares de Riofrío ${ }^{5}$ a mediados o finales de 1935. Las breves explicaciones publicadas parecen indicar que el descubrimiento se habría producido en una fecha no muy anterior a la de la adquisición de su molde 6 . El reparto de las valvas entre los

4 ..."[el molde] se halló en Linares de Riofrío (Salamanca), en el paraje denominado La Macolla. Unos trabajadores sacaban piedra para labrar sillares de granito, y al lado de un gran bloque descubrieron dos valvas que no formaban pareja; la que aquí figura, y otra un poco mayor, según me dicen. Pude adquirir una, la otra no supieron decirme donde para"... "La Macolla, que hoy persevera en medio del monte, fue un pequeño poblado en que se notan escasos vestigios de casas y algún lagar primitivo excavado en la peña (lám. xx). Es una gran pila de poco fondo, practicada en la superficie de un peñasco, con canal para la salida del líquido y un orificio a la derecha para introducir allí un grueso palo. En el país llaman lagares a estos depósitos, que son frecuentes en el término de Linares y, efectivamente, parece que no han tenido otra funcionalidad”... (Morán, 1941: 186).

5 Archivo Documental man. Exp. 1936/83. Es probable que Morán, que llegó a visitar el punto del hallazgo, pudiese adquirir la pieza a alguno de sus descubridores, o a personas que habrían conocido con detalle los pormenores del hallazgo.

${ }^{6}$ A pesar de ello, el descubrimiento se ha llegado a fechar a principios del s. xx (Santonja, 1997: 115), sin añadir datos que confirmen tal afirmación.
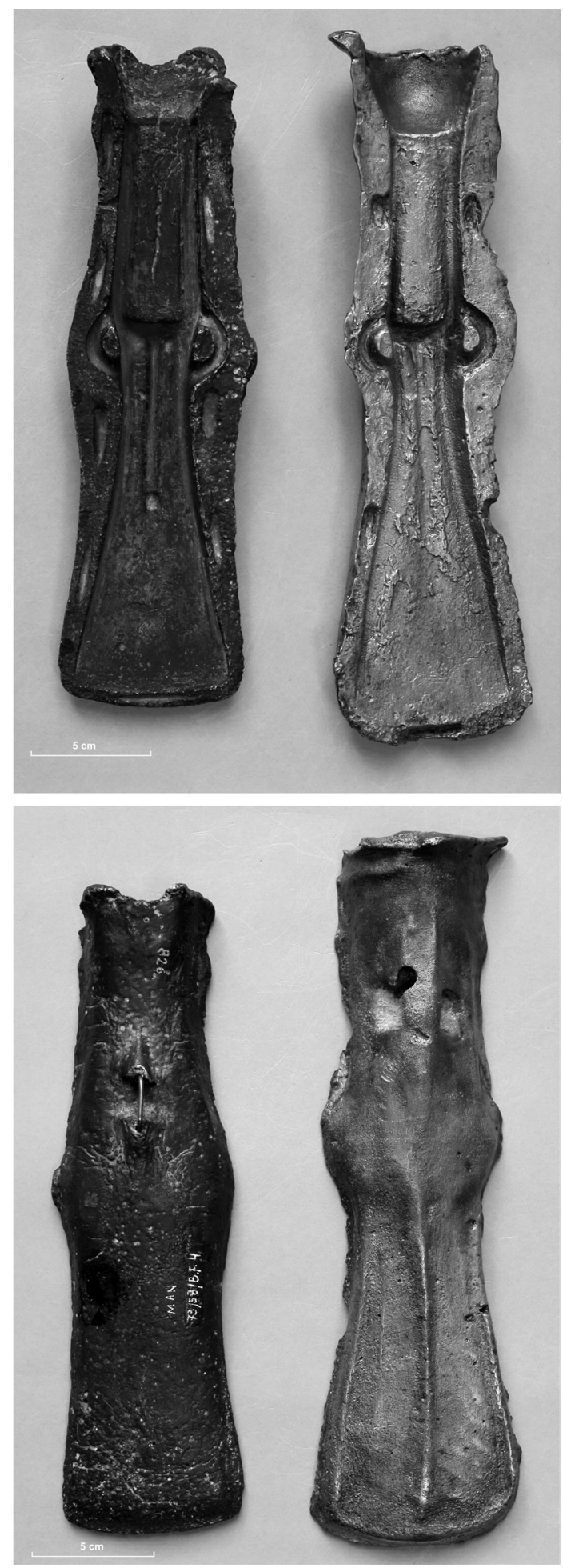

FIG. 2. Valvas de La Macolla: a la izquierda la conservada en el MAN y a la derecha, la conservada en el IVDJ. 


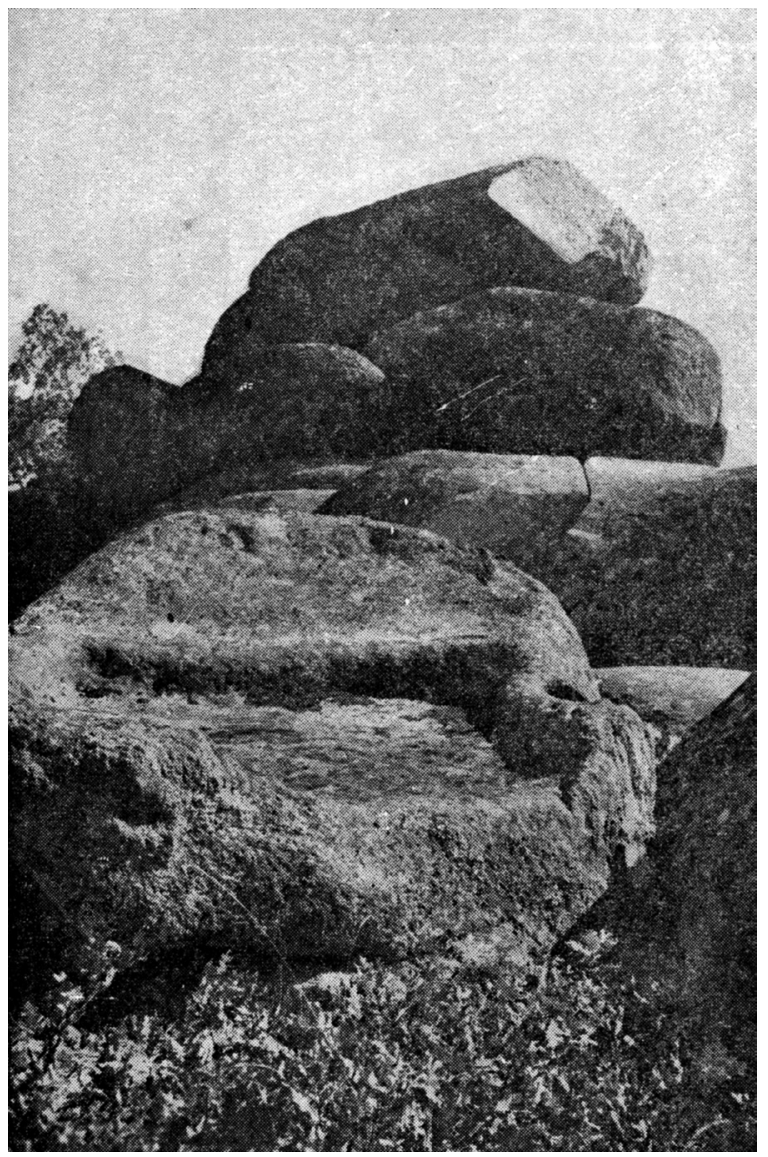

Fig. 3. Afloramiento rocoso en el paraje de La Macolla, interpretado como el lugar en el que apareció este conjunto (según Morán, 1941).

descubridores explicaría su rápida dispersión y el desconocimiento de Morán del paradero del segundo ejemplar, que contrasta a su vez con sus acertados comentarios sobre las características de los objetos (Morán, 1941: 186; 1942: 149).

Poco tiempo después, Morán (1942: 149, n. 1) informa del ingreso de la segunda valva en el $\mathrm{IVDJ}^{7}$ y de la donación, en junio de $1936^{8}$, del ejemplar de su propiedad al man. Antes de enviarla a Madrid, el investigador encargó una reproducción de

..."al lado de un bloque encontraron dos valvas, ésta de que hablo y otra un poco mayor que, naturalmente, no formaban juego. Pude adquirir una; la otra no saben decirme donde para [n. 1: Después de escrito lo que precede, hemos sabido que la adquirió el Museo de Valencia de Don Juan, donde se conserva”] (Morán, 1942: 149).

8 Archivo Documental man. Exp. 1936/83. la valva (Morán, 1942: 149, n. 2) ${ }^{9}$, que utilizó para elaborar, al menos, dos réplicas de hachas de talón (Fig. 4A y B) que ilustraron algunos de sus trabajos (1941: 188, fig. 1, n.o 6 y lám. 2; 1942: 151, fig. 11 , n. ${ }^{\text {s }} 4-5$, y fig. 13$)^{10}$.

\subsection{Los problemas de investigación}

\subsection{1. 'La valva inédita' del Instituto Valencia de Don Juan (Madrid)}

Los datos del ingreso anotados por su entonces director, M. Gómez-Moreno ${ }^{11}$, permiten deducir que la pieza se compró en el mercado de antigüedades, procedente de una venta previa. Así lo indicaría que formara parte de un pequeño lote compuesto por "una moneda visigoda y otra de Felipe $\mathrm{v}$ y un molde de hacha de bronce, procedente de Linares de la Sierra (Salamanca)", ofertado al IVDJ por "D. ${ }^{\text {a }}$ Edelvina García", nombre que hay que asociar con el establecimiento Casa Etelvina García ${ }^{12}$. Este lote fue adquirido por 175 pesetas en septiembre de 1935 .

El inicio de la Guerra Civil, y el cierre temporal del Instituto durante ese período, explican la falta de difusión de este ingreso y el desconocimiento del paradero de la valva por parte de Morán (1941: 186), que no logra acceder al molde hasta mediados de los años 40 (Morán, 1945: 173 y 1946: 44), aunque no dedicaría ningún trabajo al ejemplar. En la práctica, solo una fotografía (Fig. 4c), incorporada sin datos adicionales a un trabajo general de Carriazo sobre la

9 "Desde luego no hay ejemplares de este tipo en el Museo de Lisboa, ni en el de Saint Germain-en-Laye, ni tampoco en nuestro Museo Arqueológico Nacional a donde yo he mandado éste como regalo, quedándome con una reproducción que me hizo el artista D. José Domínguez" (Morán, 1942: 149, n. 2).

${ }_{10}$ Esta reproducción habría estado depositada en el Seminario de Arqueología de la Universidad de Salamanca al menos hasta mediados de los ańos 70 (Rauret, 1976: 145 y lám. xxvi).

11 Archivo documental IVDJ, Tomos de adquisiciones, vol. IX, n. ${ }^{\circ} 420$ y Libro mayor, n. ${ }^{\circ} 420$.

12 Este establecimiento donó o vendió durante años materiales salmantinos y de otros puntos de la Meseta a instituciones como el Museo del Pueblo Español o el propio IVDJ, como por ejemplo una pátera visigoda de Cardeñosa (Ávila), en 1944 (Archivo Documental IvDJ, Tomos de adquisiciones, vol. $\mathrm{x}$, n. ${ }^{\circ}$ 476). La procedencia anotada durante la adquisición es errónea, pudiendo quizá referirse a la 'Sierra de Linares'. 
Edad del Bronce (1947: 795, fig. 621), constituyó durante años el único documento de referencia para su estudio (Maluquer, 1958: 74 , n. 14).

\subsubsection{La donación de Morán y la 'desaparición' del molde del Museo Arqueológico Nacional}

A principios de los años 50, J. Maluquer (1950: 19) alude a los problemas existentes para la investigación de este hallazgo, que se incrementarán a mediados de esa década, cuando la valva donada por Morán -cuyo ingreso en el MAN en 1936 quedaba aparentemente confirmado por los propios inventarios del Museo- ${ }^{13}$ pasa a citarse como "en paradero desconocido" (Maluquer, 1956: 70). No contaremos con nuevos datos sobre los moldes hasta finales de los años 70 (Monteagudo, 1977: 197, taf. 86, 1246 y 1247).

Las situaciones que dieron lugar a estas noticias (Maluquer, 1958: 80, n. 17 o Rauret, 1976: 145, entre otros), así como los acontecimientos posteriores, no han sido todavía explicados. La documentación estudiada confirma que a mediados o finales de junio de 1936 Morán envía su ejemplar al MAN, considerándolo como el lugar más adecuado para su conservación. La llegada de la valva está reflejada en el expediente 1936/83 del archivo documental del MAN. Dicho expediente incorpora un inventario de los materiales enviados, elaborado por el propio Morán el 23 de junio de 1936. Se trata de piezas mayoritariamente procedentes de los dólmenes

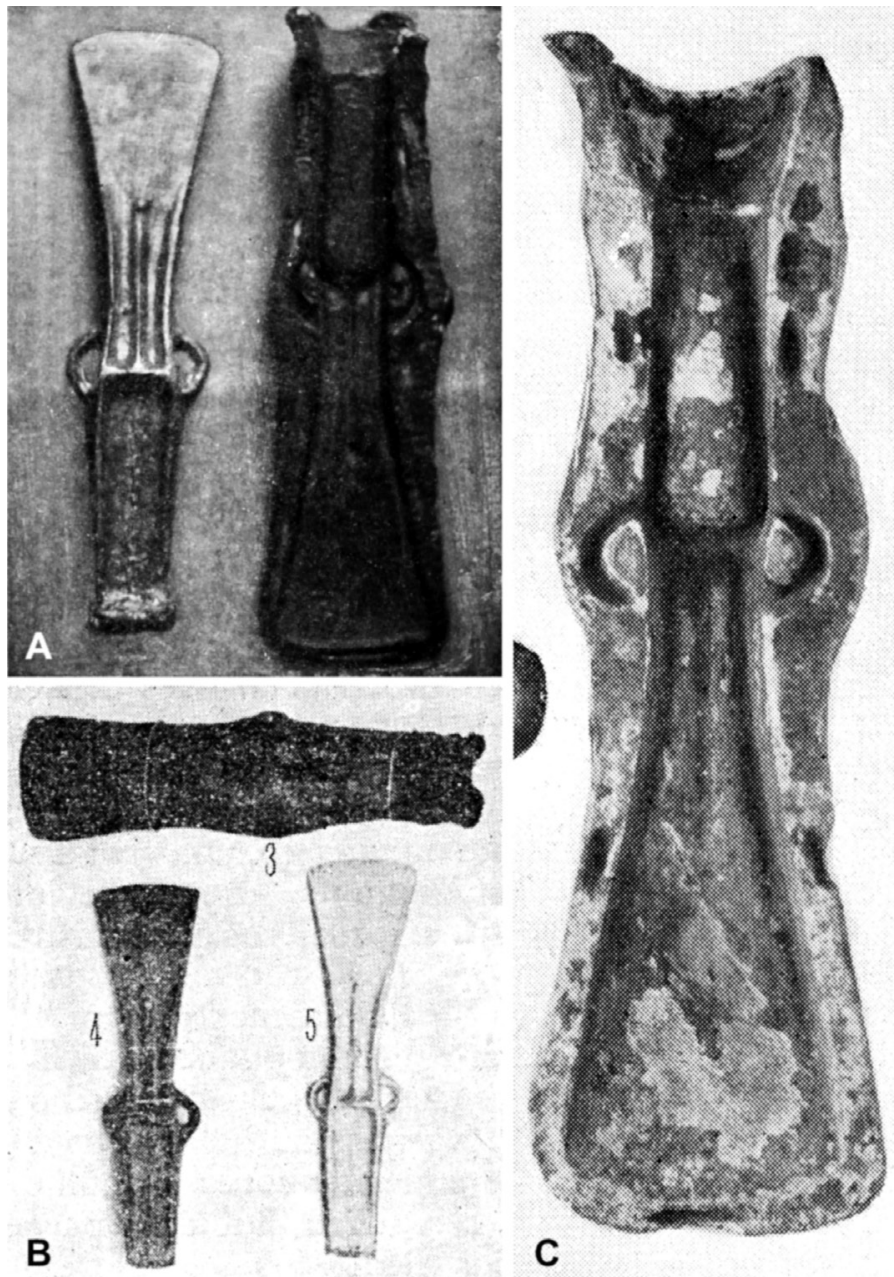

Fig. 4. Imágenes publicadas del hallazgo: $A)$ y B) hachas de talón reproducidas por Morán (1941 y 1942) junto a la valva actualmente conservada en el MAN; C) fotografía de la valva conservada en el IVDJ hacia los años 40 (segun Carriazo, 1947).

y Antigüedades (JSEA), receptora real del envío, en cuyo fondo documental se conserva una carta que acompañaría originalmente al inventario de Morán y que el investigador -por aquellos años comisionado para la excavación de dólmenes en la provincia de Salamanca- escribe el 23 de junio a F. ÁlvarezOssorio, secretario de la JSEA y director del MAN ${ }^{15}$.

15 Archivo Documental MAN. Ref: JSEA/1936/10. Agradecemos a D. a Aurora Ladero, responsable del Archivo y autora de la catalogación de este fondo, el acceso a esta documentación que hasta la fecha permanecía inédita. 
En la carta, Morán también alude a la valva ${ }^{16}$, que remite con el resto de los materiales ese mismo día. Sin embargo, lo más interesante para la cuestión que nos ocupa son dos notas añadidas al documento, una vez recibido en Madrid. La primera, manuscrita, nos confirma, entre otros asuntos, la recepción de la caja ${ }^{17}$. La segunda, mecanografiada, informa que esta fue contestada el 29 de junio de 1936.

Es preciso poner estas anotaciones en contexto. Apenas tres semanas antes del inicio de la Guerra Civil en Espańa, la caja conteniendo la valva de Morán había llegado al MAN, donde todavía se encontraba sin abrir. No volvemos a tener noticia de estos materiales durante el desarrollo de la contienda hasta que, finalizada esta, un acta firmada el 16 de mayo de 1939 por B. Taracena, a la sazón director del Museo, C. M. a del Rivero y L. Vázquez de Parga, conservadores del mismo, nos señala la apertura de varios cajones depositados en el MAN y que figuraban "como de la Junta de Excavaciones". En el primero de los contenedores se inventaría, entre otros objetos, "una caja conteniendo un envío de C. Morán al Museo Arqueológico" ${ }^{18}$, así como documentación y otros materiales arqueológicos, mencionándose los procedentes de las excavaciones realizadas por Domingo Sánchez en Irueña (Salamanca).

Al día siguiente, otra acta nos informa de la entrega a la recién creada Comisaría General de Excavaciones Arqueológicas (CGEA), a petición de su comisario general, J. Martínez Santa-Olalla, de diversos efectos de la extinta JSEA depositados en el MAN, entre los que se distinguen claramente algunos de los materiales citados en el acta del día anterior y que acompañaban a los de Morán ${ }^{19}$. Aunque en esta acta de 17 de mayo de 1939 no se citan materiales arqueológicos, un año después, en otro documento fechado el 27 de junio de 1940 y firmado por el propio Martínez Santa-Olalla ${ }^{20}$, la CGEA solicita al

16 "Lo que me parece más importante de lo que mando es el molde, que no es de mis excavaciones. Pero creo que su puesto es ahí mejor que en mi poder. Yo me quedo con una imitación que me ha hecho un amigo. De todo lo demás hay ejemplares ya en el Museo; molde de esa clase no lo hay ¿Es cierto?" (Archivo Documental man. Ref: JSEA/1936/10).

17 "Se ha recibido la caja que todavía no ha sido abierta" (Archivo Documental Man. Ref: JSEA/1936/10.

18 Archivo Documental man. Exp. 1939/30.

19 Archivo Documental Man. Exp. 1939/5.

20 Archivo Documental MaN. Exp. 1940/39.
MAN que recoja de sus locales los materiales de Irueña que, como hemos indicado, compartían caja con los enviados por Morán. Esto nos permite suponer, con cierta garantía, que estos también fueron transferidos a la CGEA en 1939.

\subsubsection{El 'reingreso' del molde en el Museo Arqueológico Nacional}

Los avatares por los que pasa esta valva se vuelven más confusos a partir de esta fecha. Pocos años después, O. Gil Farrés incluirá el molde de Linares de Riofrío en su listado de los materiales ingresados en el MAN entre 1935 y $1942^{21}$. Sin embargo, dado que buena parte de estos materiales se encontraban embalados en el momento de hacer dicha relación, hay buenas razones para pensar que esta fue elaborada a partir de la documentación del Archivo, y no a la vista de los propios objetos. Es significativo que ninguno de los materiales del envío de Morán de 1936 recibiera, ni entonces ni después, número de registro ni de inventario.

A falta de nueva documentación, solo podemos especular con las razones por las que los materiales de Morán no fueron devueltos por Martínez SantaOlalla al MAN. Tampoco está claro qué sucede posteriormente con este molde, que pudo pasar a conservarse en el Instituto Arqueológico Municipal de Madrid, fundado en 1953, y del que Santa-Olalla fue nombrado director vitalicio, llegando a depositar en ella parte de su colección particular (Quero, 1996: 197). Esta hipótesis, que deberá ser contrastada, explicaría que Monteagudo ubicase la valva en dicho Instituto (1977: 197 y 285), señalando su pertenencia a la colección Santa-Olalla.

En cualquier caso, la valva de Morán 'reingresa' finalmente en el MAN a mediados de los 70 , junto con los materiales de la colección de J. Martínez Santa-Olalla, comprada por el Estado a los herederos del investigador ${ }^{22}$, fallecido en 1972. Entre los materiales adquiridos se han identificado otras piezas que también formaron parte del envío original de Morán de 1936, como, por ejemplo, algunas procedentes del dolmen de Linejo.

21 Inventarios realizados en 1942 , que dan cuenta de los materiales ingresados desde 1935 (Archivo documental MAN. Exp. 1942/97).

22 Archivo Documental man: Exp. 1973/58. Sobre esta colección véase p. ej. Presedo, 1993: 474. 
La valva ha permanecido en el MAN desde entonces, encontrándose incluso expuesta en sus vitrinas desde finales de los años setenta. Sin embargo, la información relativa a su desaparición continuó publicándose posteriormente (p. ej. Fernández Manzano, 1986: 25 o Herrán, 2008: 126), referenciándose también, aunque en menor medida, su ubicación correcta (p. ej. Armbruster, 2000: 204-205, taf. 62).

Junto a los problemas documentales, la ausencia de una revisión directa de los objetos también ha propiciado otros datos incorrectos. Por ejemplo, los moldes han sido descritos como piezas de arenisca (Fernández Manzano, 1984: 8; 1986: 25 o Santonja, 1997:

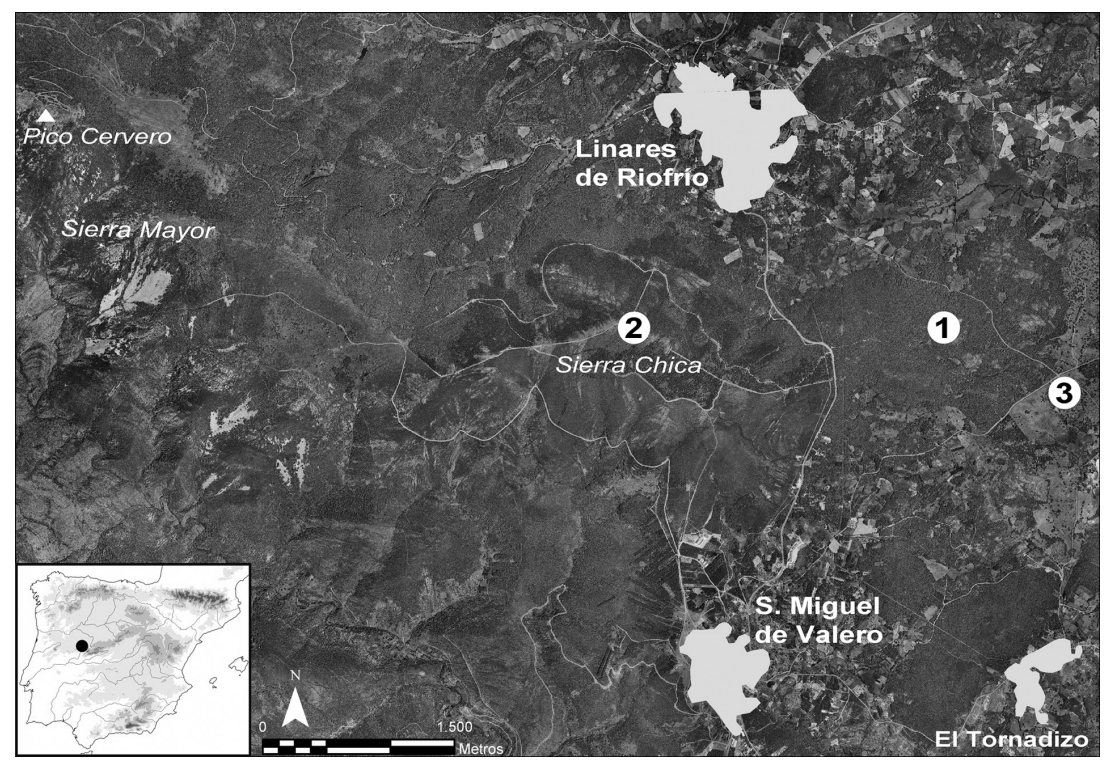

FIG. 5. Mapa de localización de los yacimientos identificados en Linares de Riofrio (a partir del Inventario Arqueológico, JCyL): 1. La Macolla; 2. Las Fraguas; 3. Majadallana (sobre ortofoto PNOA (C) Instituto Geográfico Nacional de España).

$115)$ o se ha aludido a la presen-

cia de un único molde en el hallazgo (Blas, 1975: 510; Delibes et al., 2001: 77; Fraile, 2008: 56, 64), permaneciendo la valva del IVDJ prácticamente inédita hasta hoy.

La falta de información sobre las experimentaciones de C. Morán en los años 30 también ha propiciado la publicación de datos que podrían inducir a confusión: por ejemplo, y como ya se había advertido (Herrán, 2008: 126), L. Monteagudo incorpora una de las reproducciones realizadas por Morán a su inventario de hachas de talón peninsulares (1977: 197; taf. 86, inv. 1248), aunque haciendo constar ciertas dudas, y su más que posible origen a partir del molde n. ${ }^{\circ} 1246$, es decir, de la valva actualmente en el MAN. De igual manera, la reproducción de la valva encargada por este investigador, con la que se habría elaborado esta hacha, se presenta en el estudio general de Rauret en lugar de la original (1976: lám. xxvi).

\section{El contexto arqueológico del hallazgo}

El paraje de La Macolla solo adquiere relevancia arqueológica tras las publicaciones de Morán. Aún hoy, la información sobre este lugar (los trabajos de Morán y unas pocas referencias posteriores) e, incluso, su localización exacta, es confusa, lo que dificulta su interpretación.

En el término municipal de Linares de Riofrío se han registrado tres yacimientos: La Macolla, Las Fraguas y Majadallana ${ }^{23}$ (Fig. 5), merced a las prospecciones en superficie vinculadas a la elaboración o revisión del Inventario Arqueológico de Castilla y León para la provincia de Salamanca. Los dos últimos yacimientos fueron ya mencionados por Morán durante su primera etapa de exploraciones en la provincia de Salamanca (1919: 151). En Las Fraguas, en la vertiente N de la Sierra Chica, al so de Linares, Morán (1919: 152) anota el hallazgo de "fíbulas de bronce del tipo que llaman 'fíbula hispánica”. Maluquer (1956: 70) catalogará este yacimiento como "un poblado prerromano" y menciona la aparición de cerámica y otros objetos de bronce. Por su parte, en el de Majadallana, aproximadamente a $3 \mathrm{~km}$ al sE de la población de Linares, Morán destaca la aparición de "ladrillos muy

23 Inventario Arqueológico de Castilla y León; Provincia de Salamanca; Municipio de Linares de Riofrío: n. ${ }^{\text {os }} 37-172-0001-01$ a 03. 
gruesos que deben ser romanos, pizarras labradas y fragmentos de cerámica antigua”, y apunta la existencia de algunas estructuras en las rocas del paraje (1919: 151) ${ }^{24}$.

Morán solo hará referencia a La Macolla a finales de los años 30 (vid. supra), tras el hallazgo de los moldes, destacando la existencia en este lugar de casas y "más de un lagar primitivo excavado en la peña”. En su Mapa Histórico de la Provincia de Salamanca caracterizará La Macolla como un "poblado de la Edad del Bronce, sin grandes condiciones de estrategia" (1940: 15).

En los años 50, Maluquer no recoge la existencia de este supuesto poblado en su Carta Arqueológica, aunque sí recoge el topónimo como punto del hallazgo de los moldes (1956: 70). Años más tarde, Rauret interpretará la información dada por Morán en 1940, asumiendo que el hallazgo se produjo en un poblado (1976: 143), concretamente en "un lugar próximo al recinto del poblado" (1976: 145).

Los trabajos desarrollados en los últimos años no han aclarado la cuestión. López Jiménez (2005: 348-349) sugiere la vinculación entre el poblado de Las Fraguas y Las Macollas [sic], interpretando este como un probable lugar de laboreo de metal ${ }^{25}$.

El Inventario Arqueológico provincial caracteriza el yacimiento de La Macolla ${ }^{26}$ como una loma de escasa altura, en un entorno de robles y castańos, además de existir una antigua cantera de granito. Las campañas de prospección realizadas solo han documentado la existencia de algunos fragmentos de cerámica a mano, señalando como cronología

24 “[...] unas cavidades que hay en algunas peñas [...]; unas son como sepulcros que tienen un agujero a un extremo como para salir un líquido, otros tienen forma circular, otros cuadrada, pero todos -según me dicen- con el orificio de salida” (Morán, 1919: 151).

${ }^{25} \mathrm{La}$ información arqueológica sobre Las Fraguas se limita a alguna cerámica en superficie -generalmente fragmentos a mano, lisos y sin decoración (salvo algún posible escobillado) - y a su posible paralelismo con asentamientos próximos, como el de Castil de Cabras (San Miguel de Valero), yacimiento emplazado en un saliente rocoso en la vertiente sur de la Sierra de las Quilamas y que sí cuenta con intervención arqueológica (López Jiménez, 2003: 134 y ss.).

26 Inventario Arqueológico Castilla y León; Provincia de Salamanca; Municipio de Linares de Riofrío: n. ${ }^{\circ} 37-$ 172-0001-01. probable el Bronce Medio ${ }^{27}$, pero ninguna evidencia de materiales constructivos o edificaciones.

$\mathrm{Al}$ margen de las posibles discrepancias descriptivas o cronológicas sobre los materiales procedentes de La Macolla, destaca también la disparidad de localizaciones aportadas. Según el Inventario Arqueológico, el yacimiento se situaría aproximadamente a $700 \mathrm{~m}$ al este del $\mathrm{km} 55$ de la carretera C-512, que comunica los municipios de Linares de Riofrío y San Miguel de Valero. Previamente, Santonja (1997: 115) lo había ubicado en la falda septentrional del Pico Cervero, a unos $8 \mathrm{~km}$ hacia el o (Fig. 5.1 a 3).

En conjunto, estos datos ponen en evidencia la dificultad existente tanto para la situación exacta del hallazgo, como para la interpretación contextual de La Macolla, ya sea como punto de aparición de un depósito aislado (Maluquer, 1956: 70), zona de laboreo (López Jiménez, 2005: 348-349) o poblado (Morán, 1940; Rauret, 1976: 145). Lamentablemente Morán nunca aportó una localización precisa más allá de la descripción general del entorno inmediato del hallazgo y de una fotografía (Fig. 3) poco definitoria.

\section{Estudio de los materiales}

\subsection{Estudio formal}

1. Museo Arqueológico Nacional, Madrid (Fig. 2, izq.; Figs. 6, 7 y 12).

Inventario: $1973 / 58 / \mathrm{BF} / 4$.

Documentación: Archivo Documental MAN. Expedientes: 1936/83; JSEA/1936/10; 1939/5; 1939/39; 1940/39; 1942/97; 1973/58.

Ingreso: donación de C. Morán en 1936; reingresado en 1973 como perteneciente a la colección Martínez Santa-Olalla.

Dimensiones y peso: longitud: $25,9 \mathrm{~cm}$; anchura máxima: $7,3 \mathrm{~cm}$; anchura mínima: $4,8 \mathrm{~cm}$; grosor máximo: $2,9 \mathrm{~cm}$; peso: $1622,49 \mathrm{~g}$.

Análisis de composición (Fig. 10). Referencias: PA10343A Y PA10343B (Fig. 11).

27 Se han revisado los trabajos realizados por PROEXCO S.C.L. en 1992 con motivo de la aplicación de las Normas Subsidiarias de Planeamiento y Concentración Parcelaria, y GRUPO ENTORNO S.A., para la revisión del inventario arqueológico de Salamanca, en 2004/2005. 
Descripción: valva de bronce prácticamente completa perteneciente a un molde bivalvo para fundición de hachas de talón con dos anillas, con cono de llenado en el extremo proximal. En la mitad de la cara externa incorpora una anilla de sujeción o separación, parcialmente reconstruida (Fig. 7, n. ${ }^{\circ} 1$ ).

En la cara interna, observamos parte del sistema de machihembrado que permite el encaje de las valvas. Este presenta 8 ranuras elipsoidales con sección en u que originalmente encajarían en apéndices dispuestos en la valva opuesta. Siete de las ranuras están asimétricamente distribuidas en los bordes laterales (Figs. 6 y 7, n. ${ }^{\circ}$ 5), mientras que otra, más alargada y estrecha, se sitúa en el borde del filo (Fig. 7, n. ${ }^{\circ}$ 6).

La pieza presenta algunas fracturas en la zona correspondiente al cono de llenado. En la superficie de la cara exterior se observan numerosas huellas de burbujas y grietas (Fig. 7, n. ${ }^{\text {os }} 1$ - 3), también documentadas en el estudio radiográfico. Puede apreciarse también el deterioro de la cara interna, que afecta tanto a los bordes laterales como al bebedero y a la zona correspondiente al talón del hacha (Fig. 7, n. ${ }^{\circ}$ 4).

El hacha vaciada presentaría un filo abierto, con la particularidad de incorporar una pequeña moldura semiesférica en el extremo de la acanaladura del cuerpo frontal (Fig. 7, n. ${ }^{\circ}$ 6). Las piezas resultantes del trabajo con este molde, reproducidas por Morán, presentarían aproximadamente una longitud de $22,6 \mathrm{~cm}$; una anchura máxima de $6,1 \mathrm{~cm}$ (filo), y una anchura de $5,5 \mathrm{~cm}$ en la zona de anillas (Morán, 1941: 188). En su estudio sobre las hachas peninsulares, Monteagudo clasifica estos ejemplares en el grupo 32E (León A) (Monteagudo, 1977: 197; taf. 86, n. $\left.{ }^{\text {os }} 1247-1248\right)$.

2. Instituto Valencia de Don Juan, Madrid (Fig. 2, dcha.; Fig. 4C; Figs. 8-9).

Inventario: 2889.

Ingreso: adquisición de septiembre de 1935.

Documentación: Archivo Documental IVDJ. Tomo de Adquisiciones Ix, n. ${ }^{\circ}$ 420; Libro Mayor, n. ${ }^{\circ} 420$.

Dimensiones y peso: longitud: $28,7 \mathrm{~cm}$; anchura máxima: $8,2 \mathrm{~cm}$; anchura mínima: $5,4 \mathrm{~cm}$; grosor
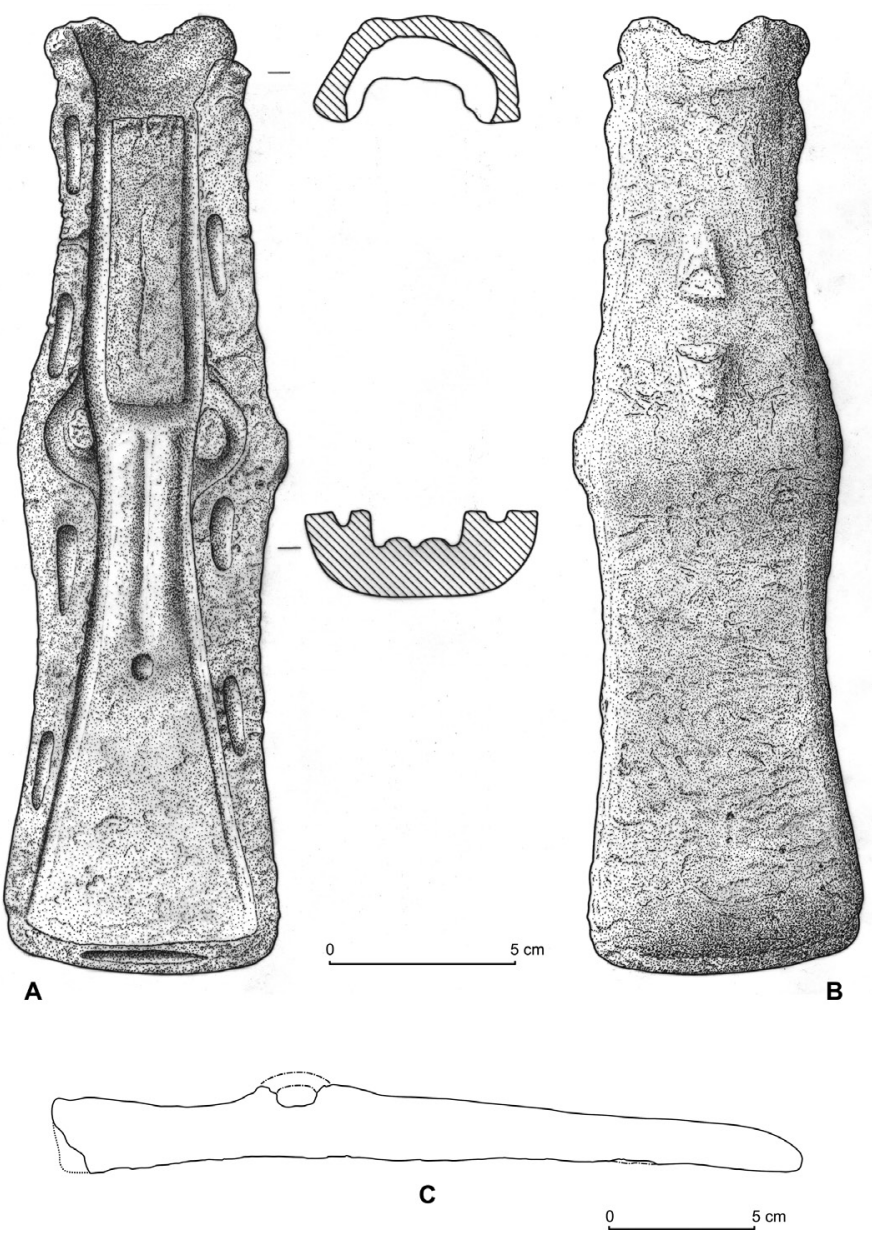

FIG. 6. Valva depositada en el MAN (dibujo OGV).

mínimo: 1,2 cm (zona frontal); grosor máximo: 3, $8 \mathrm{~cm}$ (cono fundición); grosor medio de $2,6 \mathrm{~cm}$; peso: $1691,4 \mathrm{~g}$.

Análisis de composición: Fig. 10. Referencias: PA11236в у PA11236c.

Descripción: valva de bronce correspondiente a un molde de tipo y función similar al anterior, aunque de mayor tamańo y algunas diferencias formales. Esta pieza también incorpora un sistema de encaje machihembrado aunque, en este caso, la cara interior presenta 5 ranuras elipsoidales con sección en ' $U$ ', cuatro dispuestas simétricamente en los bordes laterales y una quinta, más alargada, en el borde del filo (Fig. 2, dcha.; Fig. 8).

Como en el caso anterior, el ejemplar presenta una anilla para facilitar la separación de las valvas, 

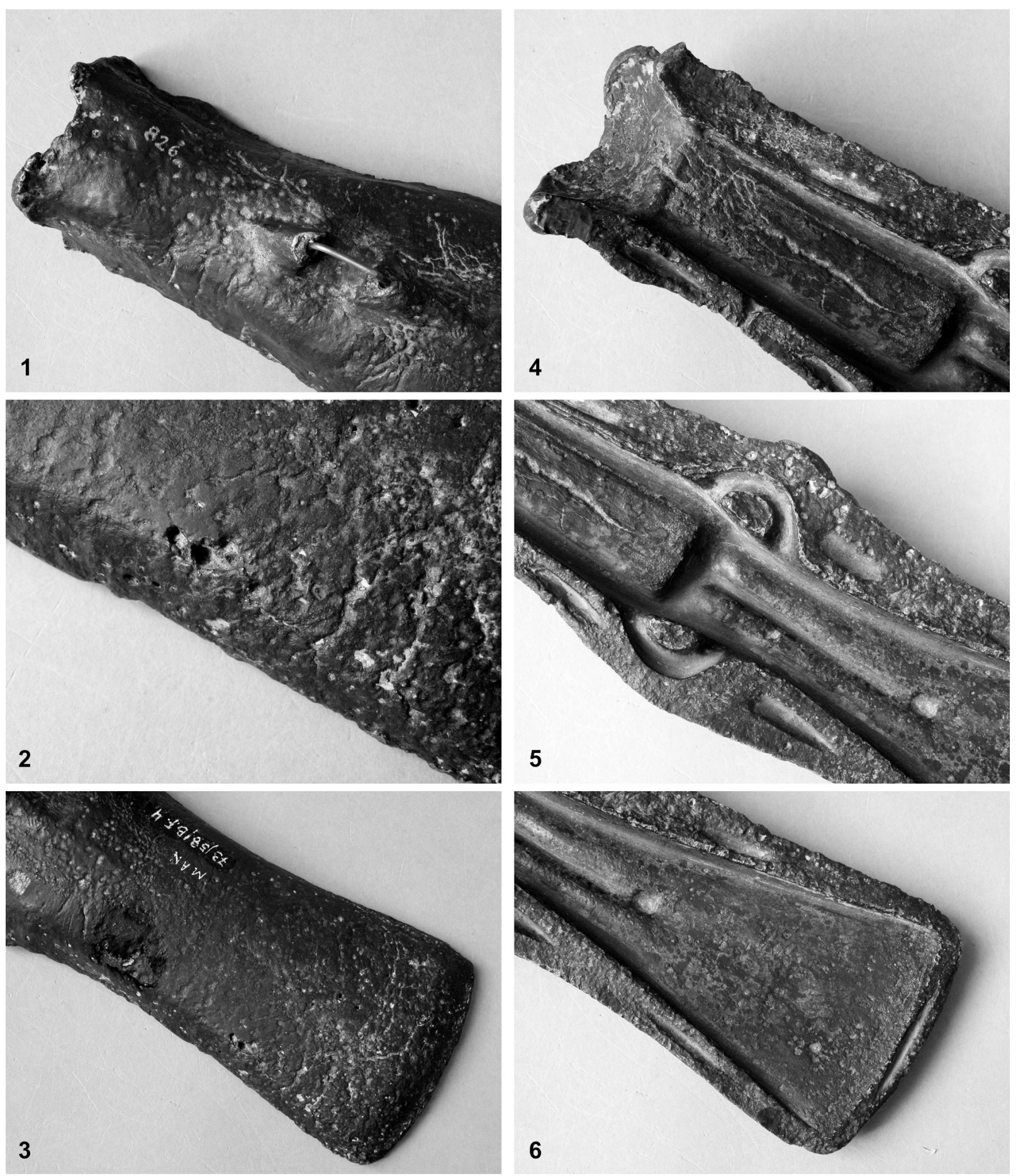

FIG. 7. Detalles de la valva depositada en el MAN. 
de sección elipsoidal y superficie plana y ligeramente apuntada, que se dispone en la zona media de la cara exterior, presentando algunas fracturas aparentemente antiguas (Fig. 9, n. $\left.{ }^{\text {s }} 1-2\right)$. El cono de llenado, situado en el extremo proximal, ofrece unas dimensiones superiores a las de la pieza del MAN y remata en un borde ligeramente moldurado y vuelto al exterior (Fig. 9, n. ${ }^{\text {s }} 1$ y 5 ).

A diferencia del ejemplar del MAN, la cara externa presenta una moldura longitudinal de sección redondeada que arranca desde la parte central del cuerpo y forma una nervadura en la frontal. El contorno de la pieza en esta zona queda aparentemente delimitado con otra leve moldura (Fig. 9, n.o 4).

Hay que señalar que la interpretación del ejemplar se ve limitada a causa de la pérdida, prácticamente por completo, de la pátina original -aún perceptible en la imagen de Carriazo (Fig. 4C) - como consecuencia de una limpieza agresiva que, muy probablemente, provocó también la fuerte abrasión y el aspecto irregular que presenta la superficie del metal en su cara interna. Destaca la alteración de la zona correspondiente al cuerpo del hacha donde se puede apreciar la erosión de la superficie, algo que podría interpretarse como posibles adherencias de metal (Fig. 9, n. ${ }^{\text {os }}$ 6-8), aunque este dato no ha podido
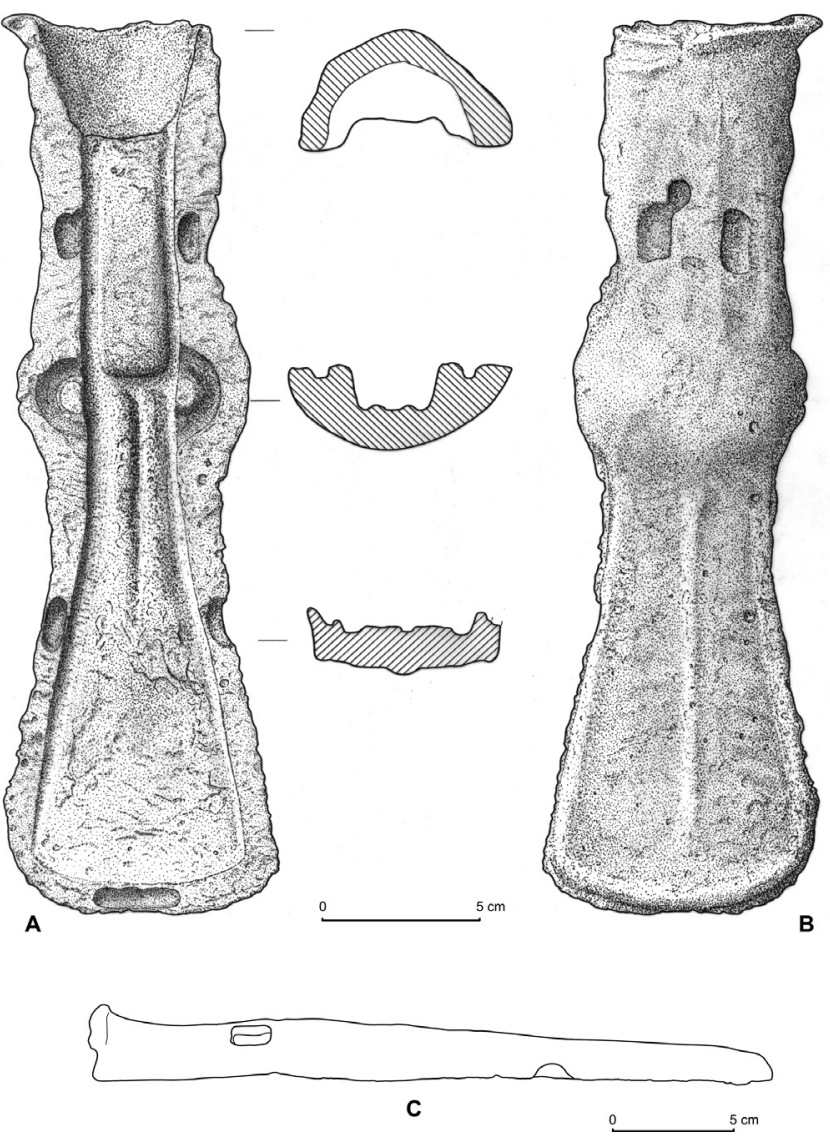

FIG. 8. Valva depositada en el IVDJ, según su estado de conservación actual (dibujo OGV). confirmarse en los análisis de composición realizados. Esas irregularidades han impedido definir con exactitud otra serie de características, como son: una posible escotadura semicircular situada en uno de los laterales (Fig. 9, n. ${ }^{\text {os }} 3$ y 7), que pudo servir para facilitar la apertura del molde tras la colada (vid. infra), y una fractura en el borde frontal que podría haber afectado a una segunda escotadura, de interpretación más dudosa (Fig. 9.4).

Las hachas fabricadas con este molde presentarían semejanzas con las obtenidas a partir de la valva del MAN, aunque de tamaño ligeramente superior, con unas dimensiones aproximadas de $24 \mathrm{~cm}$ de longitud y 6,6 cm de anchura máxima, presentando sus anillas un grosor de $1,5 \mathrm{~cm}$. Tendrían además un filo más abierto y curvo, y carecerían del apéndice semicircular que aquellas incorporan. A pesar de ello, Monteagudo las incluye en el mismo grupo tipológico $-32 \mathrm{E}-$ (Monteagudo, 1977: 197; taf. 86, n. ${ }^{\circ} 1246$ ).

\subsection{La composición del metal}

La composición elemental de los objetos fue estudiada mediante la técnica de Fluorescencia de Rayos X (XRF/X-Ray Fluorescence) ${ }^{28}$. Los resultados (Fig. 10), obtenidos a partir del muestreo de diferentes puntos de la superficie y previa limpieza de la ligera pátina superficial existente, evidencian que ambas piezas se fabricaron con bronces binarios $(\mathrm{Cu} / \mathrm{Sn})$, de una composición bastante similar. Aunque en los dos casos las aleaciones se caracterizan por una elevada presencia de estańo, se observa un porcentaje ligeramente superior de este elemento en el ejemplar del MAN (c. 20\%) que, además, ofrece

28 Se utilizó el espectrómetro METEOREX X-MET 920 MP, con fuente de $\mathrm{Am}^{241}$ y detector de $\mathrm{Si}(\mathrm{Li})$, del MAN. 
128 Ó. García-Vuelta, F. Cuesta-Gómez, E. Galán Domingo e I. Montero-Ruiz / Los moldes de fundición de bronce...
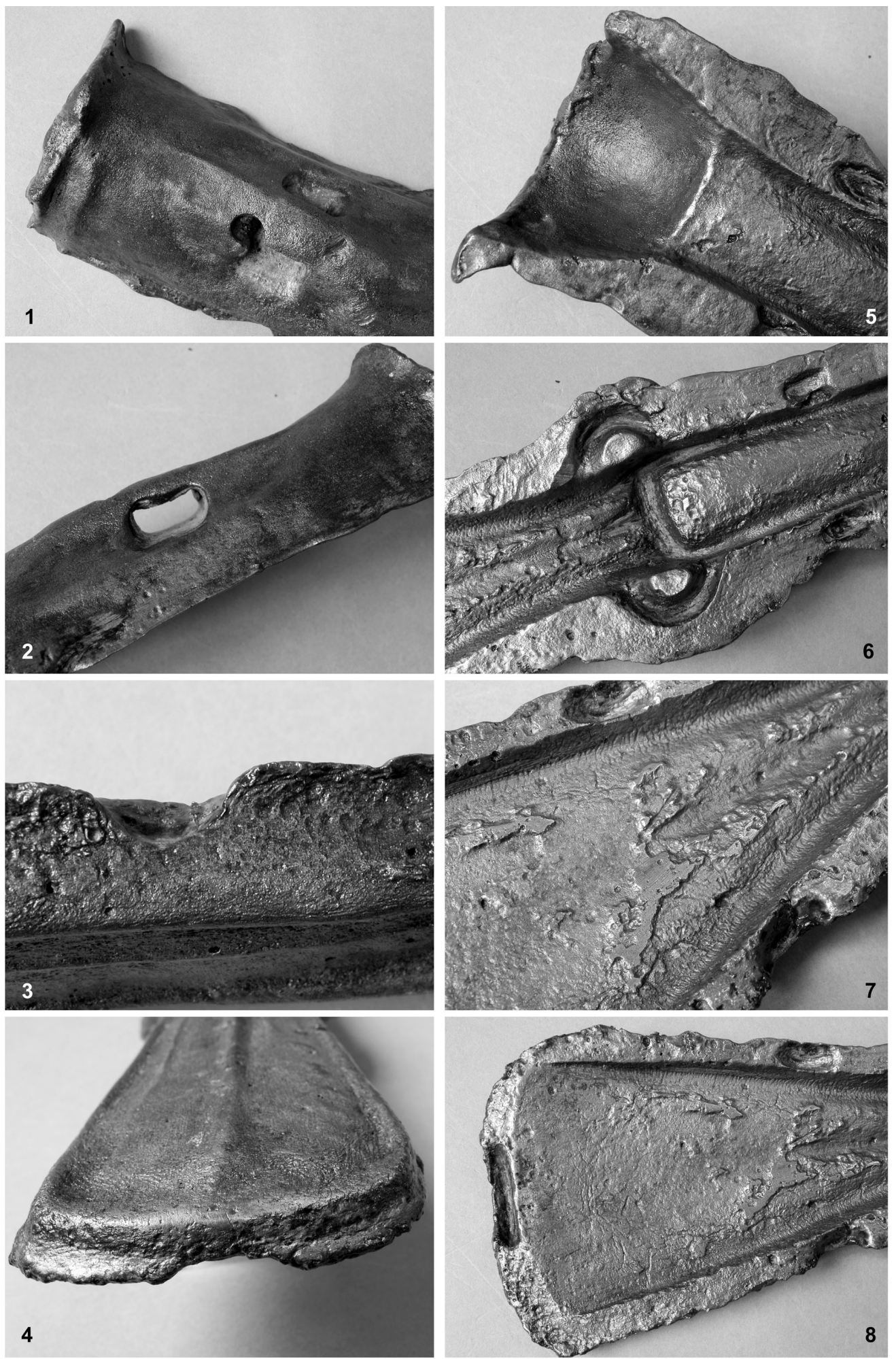

Fig. 9. Detalles de la valva depositada en el IVDJ. 


\begin{tabular}{|c|c|c|c|c|c|c|c|c|c|}
\hline Pieza & Referencia & Zona & Fe & Cu & Zn & Ag & Sn & Sb & Pb \\
\hline Molde I (MAN) & PAI0343A & bebedero (c. int.) & 0,07 & 79,6 & 0,33 & 0,028 & 20,0 & nd & 0,04 \\
\hline Molde I (MAN) & PAI0343B & centro (c. ext.) & 0,08 & 79,3 & 0,29 & 0,035 & 20,2 & nd & 0,05 \\
\hline Molde II (IVDJ) & PAI I236C & centro (c. ext.) & 0,10 & 82,4 & nd & 0,024 & 16,7 & 0,004 & 0,78 \\
\hline Molde II (IVDJ) & PAI I 236B & zona filo (c .int.) & 0,05 & 82,2 & nd & 0,023 & 17,1 & 0,007 & 0,59 \\
\hline
\end{tabular}

FIG. 10. Análisis XRF de los moldes de La Macolla (valores expresados en \% en peso).

trazas de cinc. En ambos casos, los porcentajes de plomo detectados se sitúan por debajo del $1 \%{ }^{29}$.

La valva del MAN fue objeto de un estudio analítico más detallado mediante la técnica PIXe (Particle Induced X-ray Emission) en el Centro de Microanálisis de Materiales (CMAM) de la Universidad Autónoma de Madrid (UAM) ${ }^{30}$. En este caso fueron analizados 6 puntos distribuidos a lo largo de su longitud, iniciándose la secuencia de análisis en la zona del filo. Las alteraciones documentadas en la composición de los distintos puntos muestreados (Fig. 11) pueden interpretarse como consecuencia de la propia heterogeneidad de la aleación, debido a que tasas altas de estaño $(>14 \%)$ tienden a formar fases con diferente composición durante el enfriamiento del metal ${ }^{31}$. Puede observarse también cómo este efecto es más acentuado en los análisis PIXE que en los de XRF, debido a la diferente superficie de análisis cubierta con cada una de las técnicas $\left(2 \mathrm{~mm}^{2}\right.$ frente a $25 \mathrm{~mm}^{2}$ ).

Los resultados obtenidos encuadran la composición de los dos moldes del conjunto en la tradición metalúrgica del Bronce Final de la Península Ibérica, donde predominan las aleaciones de bronce binarias, en general con altos porcentajes de estańo -especialmente en el cuadrante noroccidental-y una baja presencia de otros elementos. Solo en los momentos finales de

29 Las composiciones de La Macolla se aproximan a las documentadas para otros moldes metálicos europeos (Mohen, 1978), así como a las de un molde metálico y su correspondiente hacha monofacial del hallazgo portugués de Baióes (Valèrio et al., 2006, tablas 4-5).

30 Trabajo realizado en la línea de micro-haz externo del acelerador Tandetron de 5MV ubicado en el CMAM.

31 Este mismo fenómeno ya fue comentado y descrito por uno de nosotros en el estudio del depósito de armas de Puertollano, en Ciudad Real (Montero et al., 2002: 19-20). este período comienzan a detectarse aleaciones ternarias con plomo, y en el caso de las hachas de talón y 2 anillas, con mucho plomo (>15\%) (Sierra, 1978: 30 y ss.; Sierra et al., 1984; Montero et al., 2003).

En relación a los elementos minoritarios detectados mediante los análisis XRF, se observa una clara diferencia entre las dos valvas. En la del MAN, que apenas presenta plomo, no se detecta antimonio y aparece una pequeña cantidad de cinc, mientras que en la del IVDJ, donde este último elemento está ausente, aparecen pequeñas cantidades de antimonio y la cantidad de plomo es notablemente superior.

\begin{tabular}{|c|c|c|c|c|c|c|c|c|}
\hline Zona & $\mathbf{F e}$ & $\mathbf{N i}$ & $\mathbf{C u}$ & $\mathbf{Z n}$ & $\mathbf{A s}$ & $\mathbf{A g}$ & $\mathbf{S n}$ & $\mathbf{P b}$ \\
\hline 1 & 0,02 & 0,03 & 80,3 & 0,11 & 0,08 & 0,043 & 18,6 & 0,01 \\
\hline 2 & 0,03 & 0,03 & 82,6 & 0,12 & 0,00 & 0,062 & 16,3 & 0,03 \\
\hline 3 & 0,03 & 0,03 & 79,2 & 0,14 & 0,00 & 0,081 & 19,6 & 0,00 \\
\hline 4 & 0,03 & 0,01 & 81,0 & 0,03 & 0,03 & 0,069 & 17,8 & 0,03 \\
\hline 5 & 0,03 & 0,02 & 80,3 & 0,14 & 0,02 & 0,043 & 15,7 & 0,02 \\
\hline 6 & 0,03 & 0,03 & 82,7 & 0,06 & 0,00 & 0,000 & 16,3 & 0,01 \\
\hline
\end{tabular}

FIG. 11. Análisis PIXE de la valva conservada en el MAN (valores expresados en \% en peso).

A los estudios arqueométricos expuestos hay que añadir además un estudio radiográfico realizado en el Instituto de Patrimonio Cultural de España sobre la valva del MAN y solicitado junto a otras hachas dentro del desarrollo del proyecto BHA2001-0248. Destaca la baja calidad relativa de la fundición, observándose numerosos poros de tamaño variable distribuidos por toda la superficie de la valva (Fig. 12 ), ocasionados por un deficiente desgaseo en el proceso de colado (Antelo et al., 2010: 52-55).

\subsection{Funcionalidad y tecnologia de las piezas}

Las valvas de La Macolla constituyen dos buenos ejemplos de un tipo de herramienta metalúrgica 

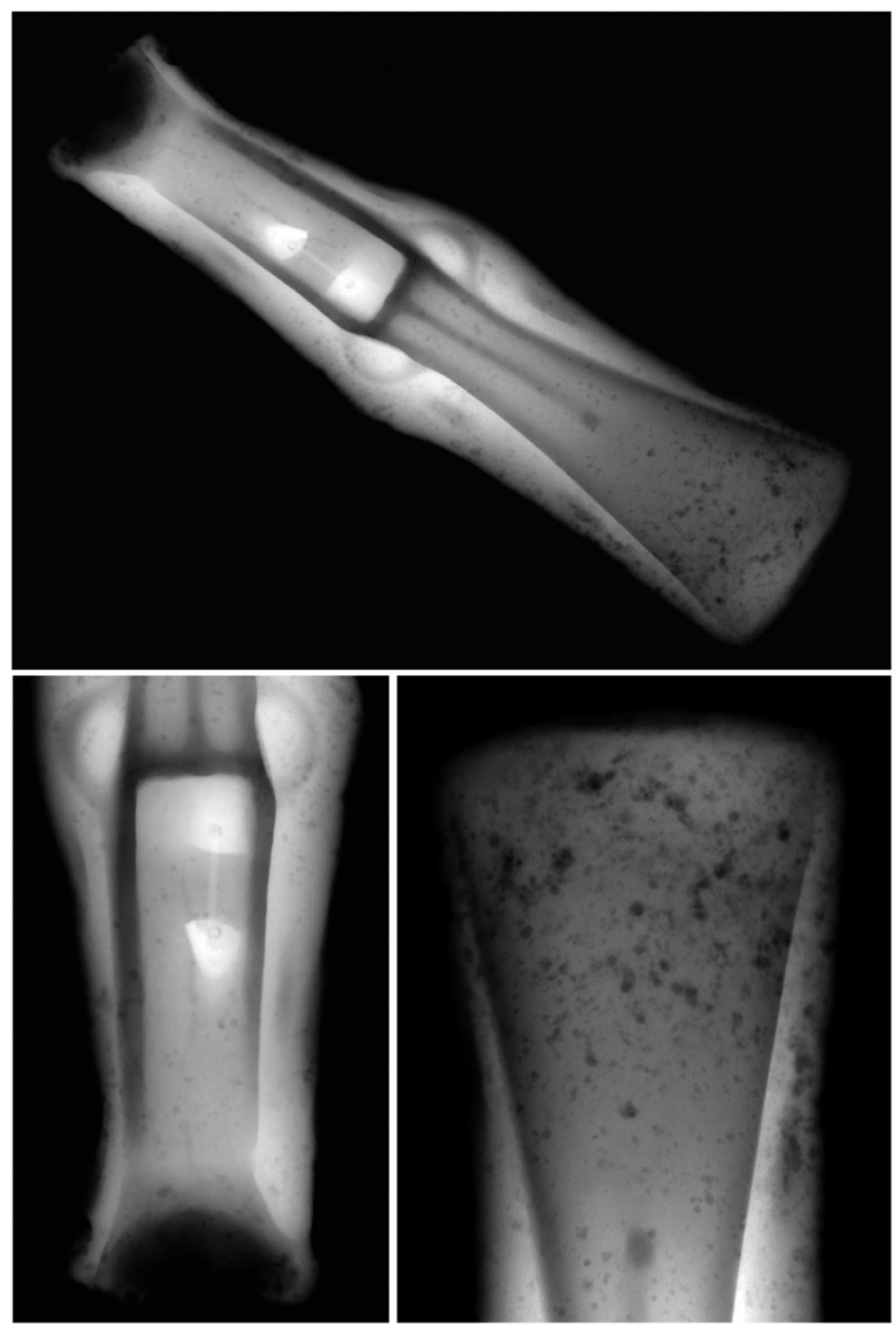

FIG. 12. Radiografias de la valva de La Macolla en el MAN: superior, imagen general; inferior izquierda, talón-bebedero; inferior derecha, zona del filo (Antelo et al., 2010).

-moldes de bronce bivalvos fabricados por fundición a la cera perdida- bien documentada en el ámbito atlántico, pero relativamente poco representada en la Península (vid. infra). Su aparición en Europa se ha fechado en el Bronce Medio, aunque es durante el Bronce Final cuando se manifiestan con más claridad (Coghlan, 1975: 59; Fleury, 1991: 272 o Mohen, 1978: 30).

$\mathrm{Su}$ idoneidad para elaborar objetos de bronce fue inicialmente cuestionada, argumentándose una serie de inconvenientes técnicos, como la proximidad entre los puntos de fusión de la colada y del propio molde; la dificultad -por lo anterior- para separar la pieza del molde una vez fundida; o el deterioro que los procesos de calentamiento y enfriamiento originarían en las valvas (véase Mohen, 1978: 27 o 1992: 125 o Fleury, 1991: 269. 270). Como explicación alternativa, se defendió su uso para la producción de 'modelos' de cera o de plomo, destinados a su posterior fundición a la cera perdida (p. ej. Déchelette, 1910: 184).

Sin embargo, diferentes trabajos experimentales (p. ej. Drescher, 1957; Allen et al., 1970 o Coghlan, 1975) demostraron no solo su funcionalidad para fundir objetos de bronce -hoy mayoritariamente aceptada-, sino la posibilidad de su reutilización o su capacidad para producir piezas con composiciones muy semejantes a las de los propios moldes (Drescher, 1957; Coghlan, 1975: 60; Mohen, 1978: 28$)^{32}$. De esta manera, su uso se ha relacionado con el aumento de la producción metalúrgica durante este período, ofreciendo una notable ventaja frente a otros tipos, como los moldes fabricados en arcilla, al facilitar una producción en serie de objetos (Drescher, 1957: 74; Coghlan, 1975: 59; Mohen, 1978: 21 o 1992: 129; Tylecote, 1987: 210).

Esta capacidad es, en buena medida, posible por la diferencia de temperatura que se mantiene durante el proceso de fundición entre el metal de la colada -generalmente a una temperatura inicial de $c .1000-1200{ }^{\circ} \mathrm{C}-\mathrm{y}$ el del propio molde, que no se aproximaría a su punto de fusión durante la fundición (Mohen, 1978: 28). El éxito del proceso de fundición dependerá, sin embargo, del adecuado control de las temperaturas durante la colada y el

32 En el caso peninsular, podemos apreciar por ejemplo la semejanza en las aleaciones $\mathrm{Cu} / \mathrm{Sn}$ documentadas en el molde y en su correspondiente hacha de N. ${ }^{a}$ Sra. da Guia, en Baióes (Valério et al., 2006, tablas 4-5). Vid. Fig. 17. 
posterior proceso de enfriamiento del metal, además de factores como un buen ajuste de ambas valvas y una adecuada evacuación de los gases.

Respecto a su modo de uso, la colada se realizaría a través de los conos de llenado situados en el extremo proximal. Es importante precalentar el molde -en torno a $150-200^{\circ} \mathrm{C}$ en el caso de los dedicados a la producción de hachas- para reducir los efectos del choque térmico y evitar desperfectos en el metal. Probablemente, una vez precalentado el molde se enterraría en un sustrato arenoso caliente, colocado en posición vertical o ligeramente inclinada, para evitar su movimiento y lograr una mayor homogeneidad en la colada, facilitando así la evacuación de los gases producidos durante su enfriamiento (Drescher, 1957; Coghlan, 1975: 6061; Mohen, 1978: 28-29 o 1992: 127-128).

Estas herramientas incorporan unos característicos sistemas de encaje machihembrados para el ajuste de las valvas que, con pequeñas diferencias, se han constatado en numerosos hallazgos. Como observamos en los ejemplares de La Macolla, pueden incorporar pequeñas ranuras y apéndices que encajan entre sí. Estos elementos pueden sustituirse o combinarse con la aplicación de ranuras de mayor longitud, que rodean total o parcialmente las valvas, encajándose en pestańas o lengüetas, como sucede en otros moldes metálicos peninsulares (vid. infra). Estos sistemas de encaje pudieron reforzarse también mediante la ligadura de las valvas ${ }^{33}$. Por otra parte, los moldes destinados a la producción de hachas de cubo presentarían un sistema de cierre diferente, ya que incorporan un núcleo metálico intermedio entre las valvas para conseguir el característico hueco del enmangue de estas piezas (p. ej. Tylecote, 1976: 34; 1987: 223-224). En estos casos, la colada debe realizarse por aperturas o escotaduras adicionales, al quedar parcialmente bloqueado el cono de llenado por dicho núcleo ${ }^{34}$.

33 Algunas marcas en moldes fabricados en arcilla (Mohen, 1992: 128) o las molduras con forma de cordón que decoran un molde metálico para hachas de talón del conjunto inglés de Wiltshire, en el British Museum, se han interpretado como evidencias o alusiones a estos procedimientos (Mohen, 1978: 29; Fleury, 1991: 270).

34 Aunque este sistema dificultaría en principio el proceso de evacuación de gases (Harrison, 1980: 134), el problema pudo minimizarse empleando coladas más líquidas o realizando un precalentamiento más intenso del molde (Fleury, 1991: 270).
Finalizada la colada, es importante que la pérdida de temperatura se produzca lentamente, ya que un enfriamiento brusco podría ocasionar grietas o defectos en el objeto fundido. La apertura de los moldes se efectuaría empleando las anillas situadas en la cara externa de las valvas, aunque también pueden incluirse para este fin pequeñas escotaduras. Para facilitar la separación de la pieza fundida de las valvas, las caras internas de estas pudieron haber sido recubiertas con otros materiales como carbón o $\operatorname{arcilla}^{35}$. Una vez separada la pieza se procedería a sus tratamientos de acabado.

$\mathrm{El}$ atento control de las temperaturas y del proceso de trabajo permite numerosas reutilizaciones de los moldes, aunque inevitablemente la repetición de los procesos de calentamiento y enfriamiento acaba por alterar finalmente la estructura interna del metal, volviéndolo más poroso, lo que acaba por provocar fallos en la fundición, haciendo el molde inservible (Coghlan, 1975: 61; Fleury, 1991: 269 270). La posibilidad de reutilizar estos moldes varía en función del control de los procesos anteriores y del tipo de objetos fundidos. Para el caso de las hachas de talón, se ha estimado que podrían llegar a fundirse al menos 15 piezas en un único molde (Coghlan, 1975: 61), aunque otros autores elevan este número a 30 o 50 ejemplares (Drescher, 1957: 74; Mohen, 1992: 129).

\section{El hallazgo de La Macolla y los moldes metálicos peninsulares}

Los moldes metálicos tuvieron, aparentemente, una amplia difusión en Europa occidental, documentándose desde el área atlántica al centro y norte del continente. Se emplearon principalmente para la fundición de herramientas -siendo el hacha el tipo mejor documentado- aunque se conocen también ejemplares dedicados a la producción de armas u objetos de adorno (Mohen, 1992: 129). Sin embargo, conviene destacar que su número es muy reducido en comparación con el de moldes elaborados en piedra o arcilla, lo que podría deberse a factores como la elevada cantidad de materia prima

35 Se ha indicado también que los óxidos producidos durante el proceso de enfriamiento podrían facilitar igualmente esta operación (Drescher, 1957: 58; Coghlan, 1975: 137; Mohen, 1992: 127-128). 


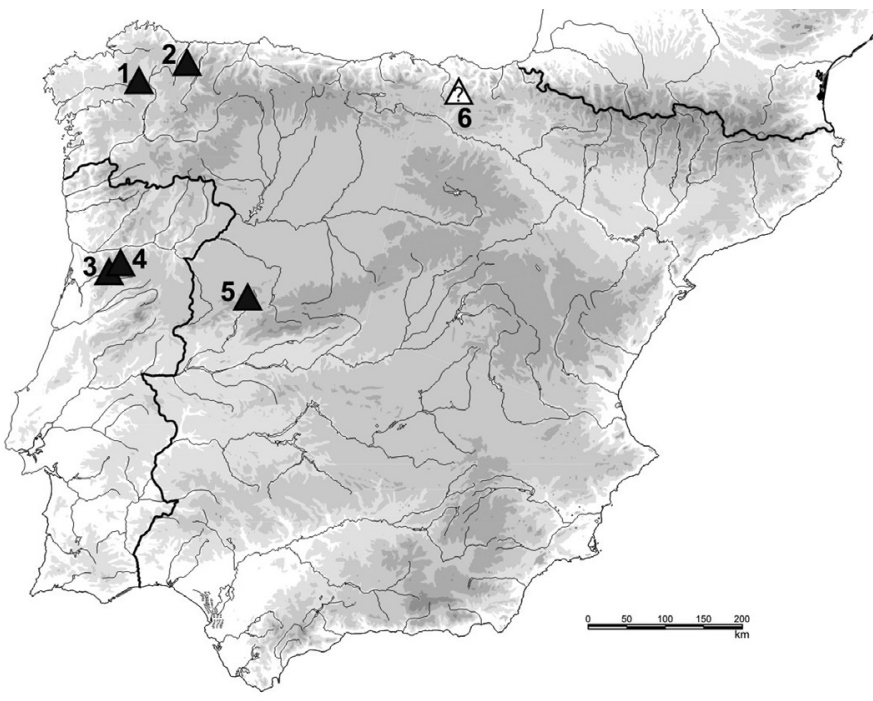

Fig. 13. Mapa de localización de los hallazgos de moldes metálicos dados a conocer hasta la fecha: 1) San Martiño de Cotá (Friol, Lugo); 2) Región de los Oscos (Asturias); 3) N.a Senhora da Guia (Baióes, Viseu); 4) Vila Boa (Castro Daire, Viseu); 5) La Macolla (Linares de Riofrío, Salamanca); 6) Vitoria.

necesaria para su elaboración -p. ej. el conjunto de cuatro valvas de La Macolla (dos juegos completos) superaría, originalmente, los $6 \mathrm{~kg}-$, que podría justificar un uso limitado a la producción de elevados números de piezas (Coghlan, 1975: 59) o la posibilidad de que el metal del propio molde fuera reciclado una vez finalizada su vida útil (Tylecote, 1987: 218), una práctica que pudo ser habitual (Mohen, 1978: 30), pudiendo estar su uso más extendido de lo que el número actual de hallazgos parece sugerir.

Aunque el patrón de los hallazgos de estos moldes es disperso, se observa una concentración de ejemplares en el área atlántica, destacando el $\mathrm{s}$ de Inglaterra y el no de Francia (Briard, 1984; Fleury, 1991: 272). Tanto en estos como en otros territorios, su tipología funcional coincide con los tipos de hachas mejor documentados arqueológicamente. Por ejemplo, en el noroeste de Francia se conocen más de 60 moldes metálicos, en su mayoría destinados a la producción de hachas de talón, de aletas y de cubo (Mohen, 1978: 30, fig. 7; 1992: 129). En el s de Inglaterra, donde predominan las hachas de cubo, son igualmente más numerosos los moldes destinados a su elaboración, en detrimento de los dedicados a la producción de hachas de talón, aunque también contamos con ejemplares para piezas de este tipo ${ }^{36}$.

El número de hallazgos de moldes metálicos de este período en la Península Ibérica es muy reducido en comparación con las regiones anteriores, señalándose su llegada a estos territorios por contactos con otras regiones europeas (Rauret, 1976: 77). Los ejemplares peninsulares comparten idénticos elementos formales y características técnicas: elaboración a la cera perdida, conos de fundición ubicados en el extremo proximal del molde; anillas de separación en las caras exteriores; y sistemas de encaje machihembrados en las interiores, con ligeras variantes en cuanto su disposición y características. Funcionalmente, predominan los moldes destinados a la producción de hachas, con una mayor representación de los ejemplares destinados a la fundición de hachas de talón, tipo que cuenta con una especial abundancia de hallazgos en la Península frente a otros, como las hachas de cubo (Hardacker, 1976; Monteagudo, 1977; Coffyn, 1985) ${ }^{37}$. En la Península Ibérica se conocen un total de 7 moldes metálicos para hachas -6 de talón y 1 para hachas de cubo-, distribuidos en 6 hallazgos. En cuanto a la tipología de las hachas, predominan las de dos anillas -5 ejemplares-, a las que hay que añadir un molde para hachas monofaciales con una anilla (Fig. 14).

Respecto a la distribución geográfica, solo tres hallazgos, además de los de La Macolla, cuentan con datos de procedencia relativamente precisos, situándose dos en la región centro-norte de Portugal y uno en Galicia, áreas que suman la mayor concentración de hallazgos de materiales metálicos

36 Puede mencionarse un molde procedente del conjunto de Hotham Carr, Yorkshire y otro del de Wiltshire (Evans, 1881: 440, láms. 528-529); fragmentos procedentes de los hallazgos de Isleham, en Cambridgeshire (Britton, 1960); y Harling, en Norkold (Wymer, 1987), o un molde incompleto descubierto en Hempnall, Norkfold (vv. AA., 2009: 46, 304).

37 Hasta donde sabemos, únicamente puede citarse en la Península un molde metálico no dedicado a la fundición de hachas, que sirvió para la fabricación de cinceles. Este ejemplar, que permanece inédito y en manos particulares, parece adscribirse a la provincia de Cáceres, apuntándose como lugar de hallazgo -aunque sin datos que lo confirmenel yacimiento de Cabezo de Araya. 


\begin{tabular}{|c|c|c|c|c|c|c|}
\hline \multirow[t]{2}{*}{ Pieza } & \multirow[t]{2}{*}{ Tipo } & \multirow[t]{2}{*}{ Conservación } & \multirow[t]{2}{*}{ Peso $(g)$} & \multicolumn{2}{|c|}{$\begin{array}{c}\text { Dimensiones }(\mathrm{cm}) \\
\text { long./anch./grosor máx. }\end{array}$} & \multirow[t]{2}{*}{ Referencia } \\
\hline & & & & Moldes & Hachas & \\
\hline Macolla 1 (MAN) & $\begin{array}{l}\text { talón, } 2 \\
\text { anillas }\end{array}$ & 1 valva & 1622,49 & $25,9 \times 7,3 \times 2,9$ & $22,6 \times 6,1$ & \\
\hline Macolla 2 (IVDJ) & $\begin{array}{l}\text { talón, } 2 \\
\text { anillas }\end{array}$ & 1 valva & 1691,4 & $28,7 \times 8,2 \times 3,8$ & c. $24 \times 6,6$ & \\
\hline Vila Boa & $\begin{array}{l}\text { talón, } 2 \\
\text { anillas }\end{array}$ & completo & 3900 & $30,1 \times 10 \times 2,1$ & long: c. 26 & $\begin{array}{l}\text { Teixeira, 1940; } \\
\text { Armbruster, 2000 }\end{array}$ \\
\hline Cotá, Friol & $\begin{array}{l}\text { talón, } 2 \\
\text { anillas }\end{array}$ & completo & $<1400$ & $18,7 \times 5,5$ & $15,5 \times 3,9 \times 2,5$ & $\begin{array}{l}\text { Vázquez, 1944; } \\
\text { Carnero, } 2007\end{array}$ \\
\hline $\begin{array}{l}\text { Sin procedencia } \\
\text { (Vitoria) }\end{array}$ & $\begin{array}{l}\text { talón, } 2 \\
\text { anillas } \\
\end{array}$ & $?$ & sin referencia & sin referencia & $24,3 \times 5,5$ & Rauret, 1976 \\
\hline N. ${ }^{a}$ Sra. da Guia & $\begin{array}{l}\text { talón } \\
\text { (monof.) } \\
1 \text { anilla }\end{array}$ & $\begin{array}{l}\text { completo; } \\
\text { se conserva } \\
\text { también } 1 \\
\text { hacha }\end{array}$ & $\begin{array}{l}\text { peso molde: } 2016 \\
\text { valva anv.: } 1041,5 \\
\text { valva rev.: } 1064,5 \\
\text { peso hacha: } 393\end{array}$ & $\begin{array}{l}26,4 \text { y } 26,6 \text { x } 5,7 x ; \\
5,2 \text { y } 5,3 \text { x } 4,1\end{array}$ & $22,6 \times 4 \times 2,1$ & $\begin{array}{l}\text { Silva et al., 1984; } \\
\text { Senna y Pedro, } 2000\end{array}$ \\
\hline Oscos & $\begin{array}{l}\text { cubo, } 2 \\
\text { anillas }\end{array}$ & $\begin{array}{l}\text { incompleto } \\
\text { (valva } \\
\text { fracturada) }\end{array}$ & sin referencias & $\begin{array}{l}\text {-valva completa: } 19,7 \\
\text { x 5,65 x 2,8 } \\
\text {-valva incompleta: } \\
14,9 \times 5,7 \times 2,65 \\
\text { núcleo: } 9,4 \times 4,2 \times \\
2,2\end{array}$ & $\begin{array}{l}14,65 \times 4,55 \times \\
\text { c. } 3 \mathrm{~cm}\end{array}$ & Harrison, 1980 \\
\hline
\end{tabular}

Fig. 14. Resumen de las dimensiones y datos básicos de los moldes metálicos para hachas de la Península Ibérica (según los datos publicados).

durante este período (Monteagudo, 1977), siendo el conjunto salmantino el que ofrece hasta la fecha una localización más meridional (Fig. 13).

Entre los moldes para hachas de talón con dos anillas, el más próximo a los de La Macolla procede del lugar de Vila Boa (Fig. 15A; Fig. 14), en Castro Daire (Viseu, Portugal). Este ejemplar también fue descubierto junto a un afloramiento rocoso. Incluye un sistema de encaje que combina ranuras y apéndices de pequeño tamaño con una ranura de mayor desarrollo en el borde correspondiente al filo (Armbruster, 2000: taf. 102, n.o 3 y 103, n. ${ }^{\circ}$ 1). Las anillas de separación, de notable tamaño, se ubican en la parte central del molde, identificándose en una de ellas una reparación (Armbruster, 2000: taf. 103, n. ${ }^{\circ}$ 2). Se han observado posibles escotaduras en los bordes laterales para facilitar su apertura (Monteagudo, 1977: taf. 93, n. ${ }^{\circ}$ 132). Las hachas producidas con este ejemplar presentarían un cuerpo de paredes rectas y filo estrecho, incorporando una moldura o apéndice semiesférico en la parte frontal, similar al del molde conservado en el MAN.
Monteagudo lo incluye dentro de su tipo 35A. Se conserva en el Museo de Arqueologia e Pré-Historia del Inst. de Antropología de la Fac. de Ciências de Oporto (Teixeira, 1940: 127; Monteagudo, 1977: 208, taf. 93, n. ${ }^{\circ}$ 1321; Armbruster, 2000: 42, 209 , taf. 102, 2-3 y 103, 1-2).

Un segundo molde (Fig. 15B; Fig. 16, sup.; Fig. 14) procede de S. Martińo de Cotá (Friol, Lugo). Es fruto de un hallazgo casual integrado, quizá, por varias piezas de bronce (Vázquez, 1953: 210-211) descubiertas bajo una peña conocida como 'Merleiros', en el lugar de 'A Pena', a orillas del río Narla. El ejemplar ofrece menor tamaño y peso que el resto de los documentados. Su sistema de encaje incluye una moldura que rodea completamente los bordes de una de las valvas, que encaja en una lengüeta situada en la opuesta (Fig. 15B). Las anillas de separación se disponen en el extremo proximal del cuerpo. Las hachas producidas con este molde fueron clasificadas por Monteagudo en su grupo 37D. Se conserva en el Museo Provincial de Lugo (Vázquez, 1944: 301 y ss.; 1953: 211; Monteagudo, 1977: 

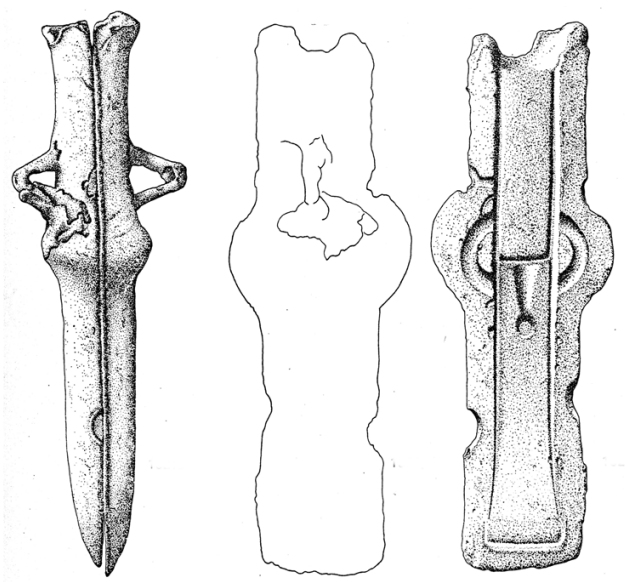

A
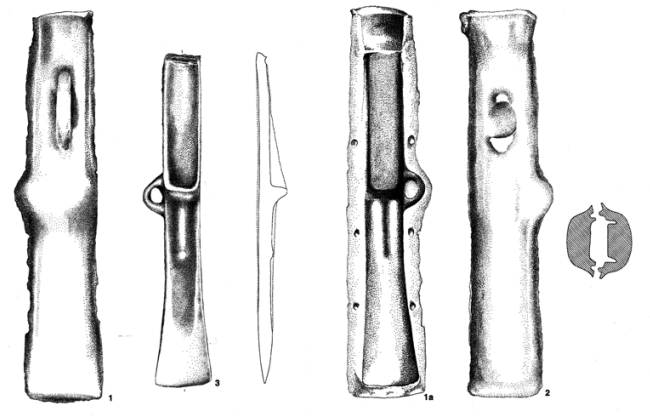

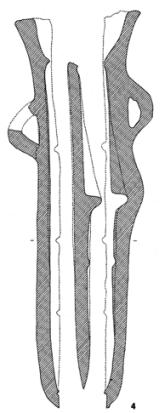

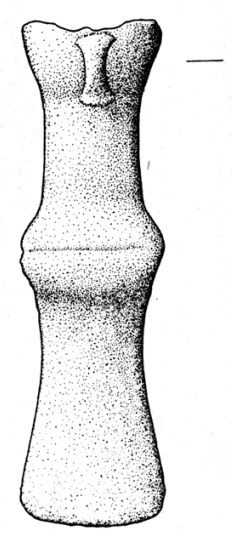

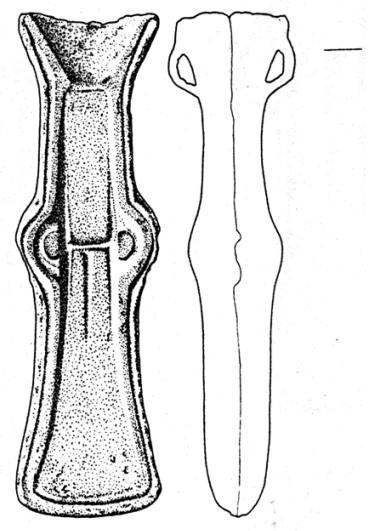

B
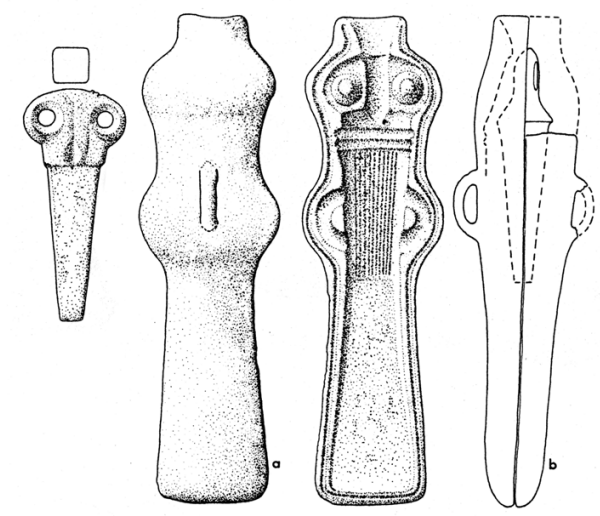

D

Fig. 15. Moldes de fundición metálicos para hachas en la Peninsula Ibérica: A) Vila Boa, Castro Daire (según Monteagudo, 1977: taf. 93, n. ${ }^{\circ}$ 1321); B) Cotá, Friol (según Monteagudo, 1977: taf. 102, n. ${ }^{\circ}$ 1416); C) Molde de N. a Sra. da Guia, Baióes y hacha monofacial (n. 3) recuperada con este (Silva, 2007: est. LXXXI); D) Los Oscos (según Monteagudo, 1977: taf. 121, n. $\left.{ }^{\circ} 1753\right)$; sin escala.

221, taf. 102, n. ${ }^{\circ}$ 1416; Armbruster, 2000: 42 y 203, taf. 50; Rauret, 1976: 145; Carnero, 2007).

El tercer molde para piezas de este tipo tiene una procedencia incierta (Fig. 14), desconociéndose el contexto de su hallazgo. Se identificó entre los restos de una carga de chatarra llegada a Vitoria $y$, lamentablemente, fue vendido a un particular cuando aún se gestionaba su adquisición para el museo de esta ciudad. Se desconoce su paradero actual. Fue publicado por A. M. ${ }^{a}$ Rauret (1976: 143 y 146), quien no pudo realizar un estudio directo de la pieza, aunque señaló que su sistema de encaje integraba ranuras y apéndices, y que el talón del hacha vaciada tendría una longitud de $7,9 \mathrm{~cm}$ incluyendo 3 nervaduras de unos $6 \mathrm{~cm}$ de longitud en su parte frontal.

El inventario de moldes para hachas de talón finaliza con un ejemplar para hachas monofaciales de una anilla perteneciente al conjunto del castro de N. Senhora da Guia, en Baiōes (São Pedro do Sul, Viseu) donde se recuperó, además, un hacha producida con este molde (Fig. 14; Fig. 15c; Fig. 16, inf.). La interpretación de este hallazgo como depósito o posible taller de fundidor continúa en 
discusión (Silva et al., 1984; Armbruster, 2000: 174 y ss., y 2002-2003: 145 y 152; Senna-Martinez y Pedro, 2000; Senna-Martinez, 2007).

El molde incorpora un sistema de encaje formado por 6 ranuras y apéndices, así como una lengüeta que recorre el borde correspondiente al filo (Silva, 2007: 283; Armbruster, 2000: taf. 20, 4). Sus anillas de separación se disponen en la parte central, encontrándose una de ellas incompleta. En la cara exterior de las valvas se aprecian huellas de martillado, interpretadas como resultado los trabajos de separación de las valvas tras la fundición (Silva et al., 1984: 77; Silva, 2007: 283). El hacha producida en este ejemplar, con filo estrecho y una nervadura con botón hemiesférico, se ha integrado en el tipo 36A de Monteagudo (Silva, 2007: 283-284, 640, est. LXxxi).

Las piezas de Baiôes eran las únicas que contaban con datos de composición, obtenidos mediante XrF (Valèrio et al., 2006). Destaca la semejanza de las aleaciones empleadas en la elaboración del hacha y del molde (Fig. 17).

Las piezas se conservan en la Univ. Católica de Viseu (Silva et al., 1984: 77-78, lám. III; Silva, 2007: 283-284, 640; lám. Lxxxi; Armbruster, 2000: 42-43,199-200, tafs. 2021; Senna-Martinez y Pedro, 2000; Valério et al., 2006: 300 y ss., entre otros).

El inventario de moldes metálicos peninsulares concluye con un ejemplar para la fundición de hachas de cubo con dos anillas, que conserva una de sus valvas incompleta (Fig. 15D; Fig. 14). Fue adquirido a finales del s. XIX para la antigua colección Soto Cortés en la región de Los Oscos (Asturias), de la que tradicionalmente se ha hecho proceder, aunque se desconoce el contexto de su hallazgo (Pericot, 1934 [1942]: 220; Blas, 1975: 503 y 1997: 33; Harrison, 1980: 131; Escortell, 1982: 47-48).

La pieza incluye anillas de separación, situadas en la mitad posterior del cuerpo y un sistema de encaje similar al de la pieza de Friol incorporando, en este caso en la parte superior de las caras interiores, apéndices y molduras para la colocación del núcleo metálico intermedio. Este elemento consta de un cuerpo troncopiramidal que se ensancha en su parte superior, de lados redondeados, incorporando dos orificios

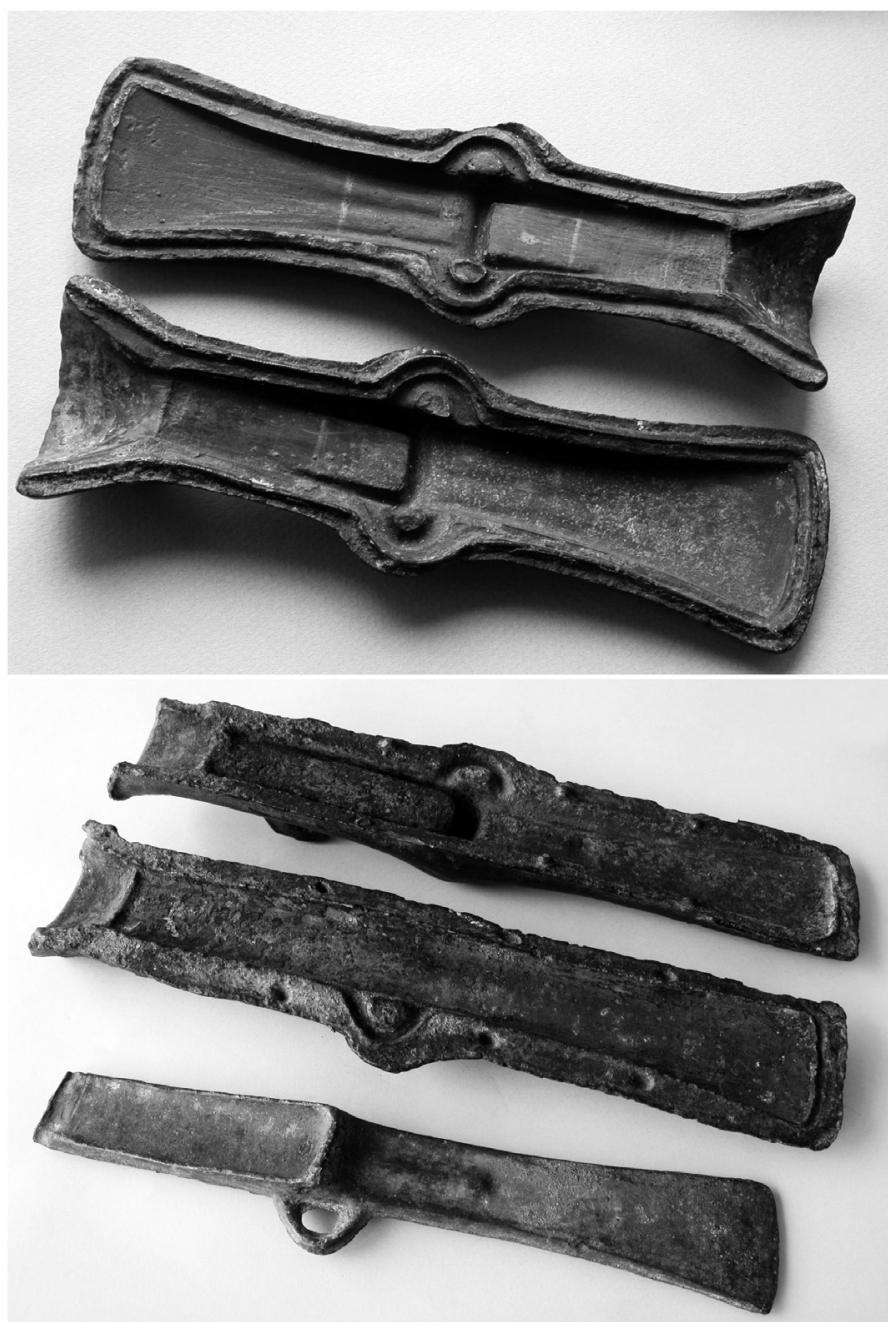

FIG. 16. Otras piezas similares: arriba, molde de San Martiño de Cotá (Friol, Lugo); abajo, molde y hacha monofacial de N. ${ }^{a}$ Sra. da Guia (Baióes, Viseu).

circulares para su fijación. La colada discurriría por unas escotaduras con sección en ' $v$ ' dispuestas en el cono de llenado de la parte posterior (Blas, 1997: 34; Armbruster, 2000, tafs. 67, 5-7 y 68). Monteagudo incluye las hachas producidas con este ejemplar en su tipo 42F (1977: 255). Se conserva en el Museo Arqueológico de Asturias (Pericot, 1934 [1942]: 220; Blas, 1975 y 1997; Rauret, 1976: 146; Hardacker, 1976: 171; Monteagudo, 1977: 255, taf. 121, n. ${ }^{\circ}$ 1753; Harrison, 1980; Coffyn, 1985: 230, pl. LVI, 3; Escortell, 1982: 47, fig. 200; Armbruster, 2000: 43, 205-206, tafs. 67 y 68). 


\begin{tabular}{|l|c|c|c|c|c|c|c|c|}
\hline \multicolumn{1}{|c|}{ Pieza } & Referencia & Zona & Fe & Cu & Sn & As & Sb & Pb \\
\hline Molde C. & ME-116 & Cara ext. & 0,25 & 76,9 & 22,4 & 0,18 & 0,08 & $<0,10$ \\
\hline & ME-116 & Cara int. & 0,22 & 81,0 & 17,7 & $<0,10$ & 0,06 & 0,66 \\
\hline Molde C. & ME-117 & Cara ext. & 0,27 & 78,7 & 20,6 & $<0,10$ & 0,06 & $<0,10$ \\
\hline & ME-117 & Cara int. & 0,72 & 77,4 & 20,1 & $<0,10$ & 0,06 & 1,47 \\
\hline Hacha monofacial & ME-118 & Sin datos & 0,35 & 81,82 & 18,0 & 0,14 & 0,04 & $<0,10$ \\
\hline
\end{tabular}

mapas en láms. 138в y 139A). Más recientemente se ha acuñado también para ellas el término de hachas de hoja trapecial (Delibes et al., 1999: 92-93), en referencia a su rasgo diferenciador más destacado.

Estas hachas se caracterizan

FIG. 17. Análisis XRF del molde (ME-116 y ME-117) y hacha de talón monofacial asociada (ME-118) de N. a Sra. da Guia; datos en \% (según Valério et al., 2006: 300 y 302, tabs. 4-5).

en general por su aspecto esbelto y equilibrado, ya que ofrecen mayoritariamente un grosor moderado y longitudes superiores a los $20 \mathrm{~cm}$. La garganta presenta

\section{La Macolla en el contexto regional: cuestiones de interpretación}

Los ejemplares salmantinos son los únicos moldes metálicos localizados hasta el momento en la Meseta Norte, una región en la que las hachas de talón están bien representadas (Monteagudo, 1977; Fernández Manzano, 1986; Delibes et al., 1999 o Herrán, 2008), y en la que se han documentado moldes fabricados con otros materiales (Rauret, 1976; Fraile, 2008). La representación de los moldes para fundición de hachas de talón es, sin embargo, mínima en estos territorios, en beneficio de los orientados a la producción de otros tipos de piezas, como las hachas planas. A los procedentes de La Macolla habría que añadir un ejemplar de arenisca del castro zamorano de La Mazada, que sirvió para la fundición de hachas con una anilla (Esparza y Larrazábal, 2000; Fraile, 2008: 59).

Queremos resaltar dos características que pueden permitir una mejor comprensión y valoración del hallazgo de La Macolla: por un lado, la tipología de los materiales fundidos en los moldes y por otro la propia localización del depósito a diferentes escalas geográficas. Como podremos ver ambas cuestiones están en buena medida interrelacionadas.

Respecto al primer aspecto, el estrictamente tipológico, las hachas de talón y doble anilla fundidas en las valvas de La Macolla corresponden genéricamente al tipo de hachas de talón más frecuente en la Meseta Norte, tal y como fue descrito por Fernández Manzano (1986: 62-71), con sus variantes de una y dos anillas, a las que este autor denominó respectivamente subtipos A 1 у в 1 . Ambas constituyen igualmente el grupo 32 de Monteagudo (1977: 189-201, láms. 80-88), con acusada distribución en la Meseta Norte y Cornisa cantábrica (ibid., los laterales bien desarrollados y el talón oscila entre formas rectas y ligeramente curvadas, situándose las anillas entre la garganta y la hoja. Esta suele alcanzar los dos tercios de la longitud total, abriéndose progresivamente hacia el filo, lo que justifica su apelativo de trapeciales, y a menudo se une al talón mediante un leve estrechamiento, bien perceptible en las piezas que nos ocupan. Normalmente, un nervio central recorre la mitad superior de la hoja, acompañado de sendos resaltes en los laterales de la misma, creando la sensación de una triple nervadura. Los filos son abiertos, oscilando según los diferentes ejemplares entre una forma prácticamente recta y curvaturas incluso bastante pronunciadas.

Todas estas características pueden verse reflejadas en los ejemplares que nos ocupan, cuyas proporciones tienen paralelos en el resto de piezas definidas dentro del mismo tipo. Así, ambas se acercan a la proporción de uno a dos tercios entre la garganta y la hoja: $36,74 \%$ a $63,26 \%$ en el caso de la valva del MAN y $33,8 \%$ a $66,2 \%$ en la del IVDJ. El estrechamiento de la hoja en la unión al talón es muy visible en la primera de las valvas citada, pero así mismo es perceptible, aunque más atenuado, en la segunda. Ambas valvas difieren también en la forma de los laterales de la hoja y en el filo, más recto en la del MAN y acusadamente más curvado en la del IVDJ. Todas estas pequeñas diferencias se aprecian igualmente en las diversas piezas conocidas de este tipo, por lo que su inclusión en el mismo no parece problemática.

Sin embargo, un rasgo en la valva conservada en el MAN introduce un elemento de cierta variabilidad en el patrón de este tipo. Nos referimos al remate del nervio central en forma de pequeña semiesfera, a modo de botón, un rasgo prácticamente desconocido en el ámbito de la Meseta Norte, salvo en el 
ejemplar, ciertamente más burdo, del depósito soriano de Covaleda (Monteagudo, 1977: lám. 84, n. ${ }^{\circ}$ 1223; Fernández Manzano, 1986: fig. 24, n. ${ }^{\circ}$ 1), que lo presenta en solo una de sus caras. Pero este rasgo del nervio central rematado en botón es característico del área centro-septentrional portuguesa, a partir del cual Monteagudo individualiza su tipo 35A (Beiras), el mismo al que pertenece el molde de bronce de Castro Daire (Monteagudo, 1977: 206208), y más exclusivo aún del área centroportuguesa, en las hachas de talón monofaciales de su grupo 36A (Arganil) (Monteagudo, 1977: 211, lám. 96), en el que se incluiría igualmente el molde procedente del conjunto de Nossa Senhora da Guia, en Baióes. No deja de ser curioso, y quizás no simplemente anecdótico, el hecho de que la mayoría de los escasos moldes metálicos conservados reflejen este detalle característico, toda vez que por demás el número total de hachas conocidas con este motivo es proporcionalmente mucho más escaso.

Así, las hachas fundidas en la valva del MAN presentan un aspecto unificador de las características tipológicas de los ejemplares peculiares de la Meseta Norte y su extensión al área cantábrica, con alguna muy expresiva del área centroportuguesa, como es el nervio central rematado en botón. Todo ello no es ajeno al propio ámbito geográfico en el que fueron halladas las piezas que estudiamos, puesto que el área salmantina se configura como una 'tierra de nadie' en la dispersión general de la metalurgia atlántica del Bronce final.

En efecto, basta con ver los diversos catálogos publicados para apreciar cómo en la Meseta Norte, las tierras al $s$ del curso del río Duero manifiestan una reducción significativa en sus inventarios de hallazgos respecto a las tierras situadas al $\mathrm{N}$ de dicho curso. Si esta consideración es válida para el conjunto de la metalurgia del Bronce final en la provincia de Salamanca (Fernández Manzano, 1986: 25-26; Herrán, 2008: 118-131), en lo referente a las hachas de talón es aún más patente (Fig. 18). En toda ella, aparte del que aquí estudiamos, solo se documentan otros seis hallazgos, todos aislados y cuatro de ellos reducidos a fragmentos ${ }^{38}$. Solo el

38 Hasta el momento, únicamente se han referenciado dos hachas de dos anillas: una pieza completa del municipio de Los Santos (Herrán, 2008: 126, fig. 86, n.o 4), y otra incompleta del pago de Zaoz, en Peñaparda (Maluquer, 1956: 91; Fernández Manzano, 1986: 25; Santonja, 1997: hacha de talón y una anilla del cercano municipio de Santibáñez de la Sierra corresponde con seguridad al tipo genérico de las piezas de Linares de Riofrío. Lo mismo ocurre en las provincias meridionales de Ávila -un solo hallazgo de hachas de talón- y Segovia -igualmente un único hallazgo-. Algo más prolífica es la situación si miramos hacia el s, con varias hachas de talón concentradas en la parte septentrional de la provincia de Cáceres, pero cuya tipología las aleja de los ejemplares que ahora nos interesan (Almagro Gorbea, 1977: 70-71), para acabar desapareciendo casi totalmente al s del Tajo, en lo que constituye un rasgo característico de la metalurgia del Bronce final en el so peninsular (Galán, 2005: 4).

Esta acumulación de materiales en torno al Sistema Central se hace aún más significativa si la relacionamos con la presencia en la misma zona de otro elemento característico de este período: las estelas de guerrero o del so. En efecto, siguiendo toda la línea del Sistema Central, encontramos una profusión de localizaciones de estelas desde las estribaciones de la Sierra de la Estrella en Portugal (Rodrigues, 1958; Curado, 1984 y 1986; Martín, 1992; Santos et al., 2011; Vilaça et al., 2011a y b), y continuando por los diversos pasos entre el área salmantina y Extremadura, de o a E: San Martín de Trevejo (García de Figuerola, 1972), Robleda (Martín, 2010), Hernán Pérez (Almagro, 1972) y Puerto de Honduras (Sanabria, 2011). Resulta tentador interpretar conjuntamente ambos fenómenos, teniendo en cuenta además el vacío que tanto hacia el N, como luego hacia el s, presenta la distribución de las hachas de talón y de buena parte de

107; Herrán, 2008: 128), de características desconocidas, reiteradamente citada pero nunca representada. Un hacha de talón con una anilla se recuperó en un punto indeterminado de la carretera entre Béjar-Sequeros, en Santibáñez de la Sierra (Morán, 1942: 153; Maluquer, 1956: 23; Monteagudo, 1977: 194, n. ${ }^{\circ}$ 1120; Herrán, 2008: 130, fig. 88, n. ${ }^{\circ}$ 2). El inventario actual se cierra con algunos fragmentos de hachas de talón, como el procedente de la zona del Cerro del Berrueco, en El Tejado (Fernández Manzano, 1986: 26; Herrán, 2008: 124, fig. 85, n.o 6); otro del sepulcro de corredor de Las Cańas, en Fuenteliante (Fernández Manzano, 1986: 25; Herrán, 2008: 125, fig. 86, n. ${ }^{\circ} 3$ ); y otro perteneciente a la hoja de un hacha de Peñaranda de Bracamonte (Monteagudo, 1977; 178, n. ${ }^{\circ}$ 1104; Fernández Manzano, 1986: 26; Herrán, 2008: 128, fig. 87, n. $\left.{ }^{\circ} 6\right)$. 


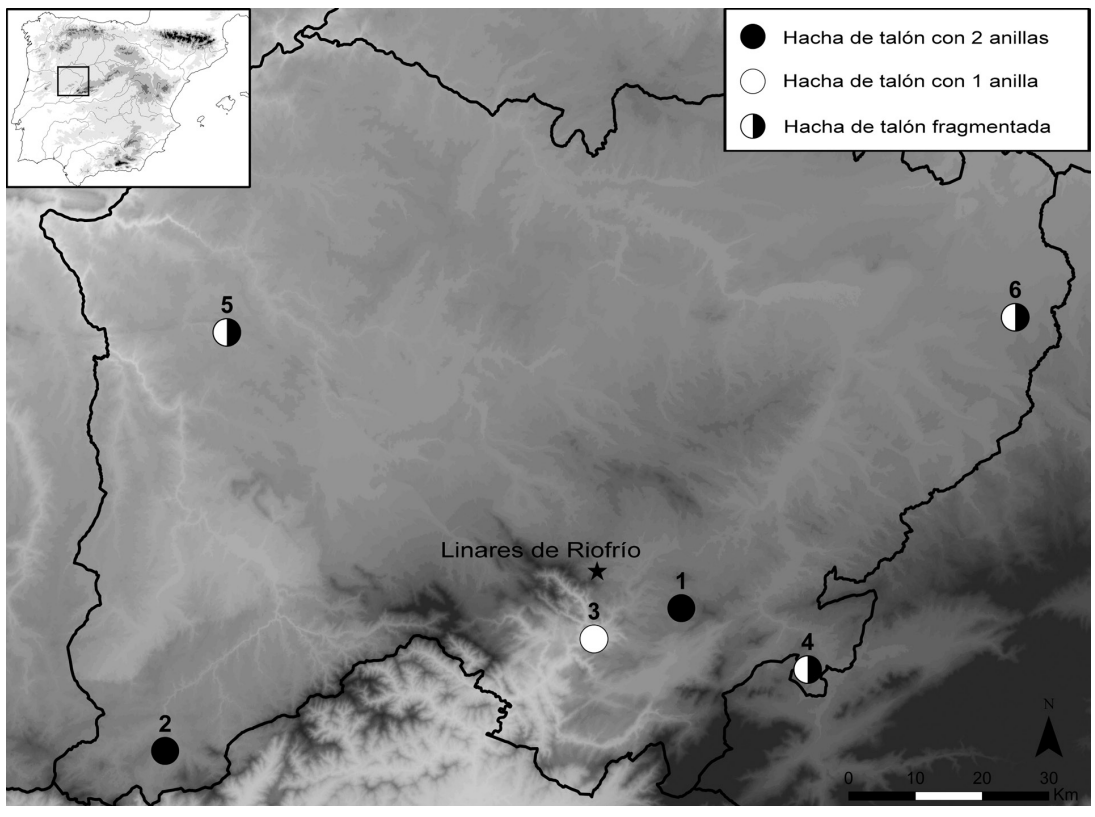

Fig. 18. Mapa de distribución de los hallazgos de hachas de talón en la provincia de Salamanca mencionados en el texto: 1. Los Santos; 2. Peñaparda; 3. Santibáñez de la Sierra; 4. Cerro de El Berrueco; 5. Fuenteliante; 6. Peñaranda de Bracamonte.

la metalurgia atlántica, excepto algunos tipos de armas. Así, podríamos plantear la existencia de algún tipo de límite entre la Meseta Norte y Extremadura en la época que nos ocupa, con el área de frontera entre ambas marcado simbólicamente por bronces y estelas (Galán, 1993: 71-72).

Sea esta o no una posible explicación para el hallazgo específico de Linares de Riofrío, nos encontramos pues ante un hallazgo excepcional en el contexto regional, cuya lectura es compleja. Dejando aparte los problemas documentales específicos expuestos en la primera parte de este estudio, la interpretación del conjunto enlaza directamente -como la del resto de los objetos de este grupo- con la complejidad de lecturas posibles para los depósitos con materiales metálicos en el ámbito atlántico, abordadas por diferentes autores (Levy, 1982; Bradley, 1990; Ruiz-Gálvez, 1995; Vilaça, 2006). Lamentablemente, el estudio interpretativo de las piezas peninsulares está limitado por la falta de datos contextuales ${ }^{39}$, careciéndose de información para dos de los hallazgos -Vitoria y Los

39 Una revisión general sobre estas cuestiones en el ámbito peninsular puede consultarse en Celis et al., 2007.
Oscos-, y contándose apenas con algunos datos para el estudio de otros tres -La Macolla, Castro Daire y Friol-. Únicamente el hallazgo de N. ${ }^{a}$ Sra. da Guia permitiría situar con seguridad uno de los moldes en el interior de un poblado, en un contexto susceptible de ser interpretado como un posible taller de fundidor (Senna-Martínez y Pedro, 2000; Senna-Martínez, 2007).

Por lo que respecta al hallazgo salmantino, y a falta de mayor información sobre un posible poblado coetáneo a las piezas en el paraje de La Macolla (vid. supra), podrían considerarse varias opciones de interpretación. Desde una perspectiva económica, el conjunto, que reúne más de 3 kg de metal, podría considerarse una ocultación/acumulación de objetos probablemente ya desechados y destinados a la refundición. Sin embargo, no hay que descartar las posibles lecturas de tipo simbólico que pueden aplicarse también a las piezas de este grupo. Diversos autores (Bradley, 1990; Ruiz-Gálvez, 1995) han llamado ya la atención sobre la relación de los depósitos de objetos metálicos de bronce -tanto en forma de piezas aisladas como de conjuntos- con lugares provistos de un especial valor simbólico o relacionados con determinadas prácticas rituales (p. ej. determinados parajes, cursos de agua o afloramientos rocosos). En ese sentido, llama la atención que tres de los cuatro hallazgos que cuentan con algún dato contextual, están directamente asociados con afloramientos rocosos -La Macolla, Castro Daire y Cotá- ${ }^{40}$. Las más recientes interpretaciones para este tipo de depósitos en el contexto peninsular se han

${ }^{40}$ Como los de La Macolla, el de Castro Daire apareció "junto dum penedo", aparentemente sin otros materiales asociados (Teixeira, 1940: 127). Las primeras informaciones sobre el de Friol apuntarían a su caracterización como hallazgo aislado entre las rocas de una peńa (Vazquez, 1944: 301), aunque posteriormente se señaló que fue descubierto en una posible estructura de lajas, quizá en compañía de otras piezas de bronce (Vázquez, 1953: 210-211). 
relacionado con su interpretación simbólica. Bacelar y Comendador (2009: 47) apoyan por ejemplo su lectura como una 'devolución' ritual de los objetos - $\mathrm{O}$ en estos casos las herramientas para producirlosal medio del que estos fueron extraídos. En la misma línea podría considerarse la interpretación como un posible depósito 'de regeneración' propuesta por Vilaça (2006: 88) para el hallazgo de Castro Daire.

El desarrollo de líneas de trabajo orientadas a recoger y sistematizar toda información contextual disponible sobre estos hallazgos dará lugar sin duda a nuevas e interesantes aproximaciones sobre esta cuestión.

\section{Bibliografía}

Allen, J. M.; Britton, D. y Coghlan, H. H. (1970): Metallurgical reports on British and Irish Bronze Age implements and weapons in the Pitt Rivers Museum. Oxford: OUP.

Almagro Basch, M. (1972): "Los ídolos y la estela decorada de Hernán Pérez (Cáceres) y el ídolo estela de Tabuyo del Monte (León)”, Trabajos de Prehistoria, 29, pp. 83-124.

Almagro Gorbea, M. (1977): El Bronce Final y el periodo orientalizante en Extremadura. Biblioteca Praehistorica Hispana, XIV. Madrid: CSIC.

Antelo, T; Bueso, M.; Gabaldón, A. y Martín Costea, A. (2010): La técnica radiográfica en los metales históricos. Madrid: Ministerio de Cultura.

Armbruster, B. R. (2000): Goldschmiedekunst und Bronzetechnik. Studien zum Metallhandwerk der Atlantischen Bronzezeit auf der Iberischen Halbinsel. Monographies Instrumentum, 15. Montagnac: Monique Mergoil.

Armbruster, B. R. (2002-2003): “A metalurgia da Idade do Bronze Final Atlântico do Castro de Nossa Senhora da Guia de Baióes (S. Pedro do Sul, Viseu)", Estudos Pré-históricos, 10-11, pp. 145-155.

Bacelar, L. y Comendador, B. (2009): "Rochas e metáis na Pré-Historia para além da físico-química”. En BETtencourt, A. M. S. y Bacelar, L. (eds.): Dos montes, das pedras e das águas. Formas de interacção com o espaço natural da pré-história á actualidade. CITCEM-APEQ, pp. 37-54.

Blas, M. A. de (1975): "Un interesante molde para fundir hachas de cubo y anillas". En Actas del XIII Congreso Nacional de Arqueología (Huelva, 1973). Huelva, pp. 507-512.

Blas, M. A. de (1997): "Molde de bronce para hachas, procedente de un desconocido yacimiento del Bronce
Final, en la zona de Los Oscos y las hachas de cubo en Asturias", Nuestro Museo, 1, pp. 33-37.

Bradley, R. (1990): The passage of Arms. An archaeological analysis of prehistoric hoards and votive deposits. Cambrigde: CUP.

Briard, J. (1984): Paleometallurgie de la France Atlantique. L'Âge du Bronze (1). Rennes: Univ. de Rennes.

Britton, D. (1960): "The Isleham Hoard, Cambridgeshire”, Antiquity, 34, pp. 279-282.

Carnero, M. O. (2007): "Molde bivalvo de Cotá". En Guía Gráfica do Museo Provincial de Lugo. Cartafol do Museo. Lugo, lám. xxx.

Carriazo, J. de M. (1947) [1963]: "La Edad del Bronce". En Menéndez Pidal, R. (dir.): Historia de España, t. I, 1 (España prehistórica). Madrid: Espasa-Calpe, pp. 755-852.

Celís, J.; Delibes de Castro, G.; Fernández Manzano, J. y Grau Lobo, L. (eds.) (2007): El hallazgo leonés de Valdevimbre y los depósitos del bronce final atlántico en la Península Ibérica. León: Jcyl-Diput. de León.

Coffyn, A. (1985): Le Bronze Final Atlantique dans la Péninsule Iberique. Bordeaux: CNRS.

Coghlan, H. H. (1975) [1951]: Notes on the prehistoric metallurgy of copper and bronze in the Old World. Oxford: oup.

Curado, F. P. (1984): "Uma nova estela do Bronze Final na Beira Alta (Baraçal, Sabugal, Guarda)”, Arqueología (GEAP), 9, pp. 81-84

Curado, F. P. (1986): "Mais uma estela do Bronze Final na Beira Alta (Foios, Sabugal, Guarda)", Arqueología (GEAP), 14, pp. 103-109.

Déchelette, J. (1910): Manuel d'Archéologie Préhistorique, Céltique et Gallo-romaine, t. II. Paris: Picard.

Delibes de Castro, G.; Fernández Manzano, J.; Fontaneda, E. y Rovira, S. (1999): Metalurgia de la Edad del Bronce en el piedemonte meridional de la Cordillera Cantábrica: La Colección Fontaneda. Monografías: Arqueología en Castilla y León, 3. Valladolid: JCyL.

Delibes de Castro, G.; Fernández Manzano, J.; Romero, J.; Herrán Martínez, J. I. y Ramírez, M. L. (2001): "Metal production at the end of the Late Bronze Age in the central Iberian Peninsula", Journal of Iberian Archaeology, 3, pp. 73-95.

Drescher, H. (1957): "Der Bronzeguss in formen aus Bronze", Die Kunde, 8 (1-2), pp. 52-75.

Escortell, M. (1982): Catálogo de las edades de los metales del Museo Arqueológico de Oviedo. Oviedo.

Esparza, Á. y LarrazÁbal, J. (2000): “El castro de La Mazada (Zamora). Elementos metálicos y contexto peninsular". En Actas III Congreso de Arqueología Peninsular, vol. 5. Porto, pp. 433-469.

Evans, J. (1881): The Ancient bronze implements. Weapons and ornaments of Great Britain and Ireland. London. 
Fernández Manzano, J. (1984): “Armas y útiles metálicos del Bronce Final en la Meseta Norte", Boletín del Seminario de Estudios de Arte y Arqueología, 50, pp. 5-25.

Fernández Manzano, J. (1986): Bronce final en la Meseta Norte española: el utillaje metálico. Valladolid: JCyL.

Fernández Manzano, J.; Herrán, J. I. y Rovira, S. (2005): "Los depósitos metálicos burgaleses y la metalurgia del Bronce Final en la Meseta norte: algunas cuestiones", Boletín del Seminario de Estudios de Arte y Arqueología. Arqueología, 71, pp. 137-159.

Fleury, L. (1991): "Les moules de l'Âge du Bronze en France Atlantique et dans les Îles Britanniques: aspects technologiques et culturels". En Chevillot, C. y Coffyn, A. (dirs.): L'Âge du Bronze Atlantique: ses faciès, de l'Ecosse à l'Andalousie et leurs relations avec le Bronze continental et la Méditerranée. $I^{e r}$ colloque du Parc Archeologique de Beynac. Beynac-et-Cazenac: As. Musées du Sardalais, pp. 267-275.

Fraile, A. (2008): "Moldes de fundición de las edades del Bronce y del Hierro en la submeseta norte española”, Boletín del Seminario de Estudios de Arte y Arqueología. Arqueología, 74, pp. 48-73.

Galán, E. (1993): Estelas, paisaje y territorio en el Bronce Final de la Península Ibérica. Complutum Extra, 3. Madrid.

Galán. E. (2005): "Noroeste y Suroeste: dos ámbitos para el tránsito". En Perea, A. (dir.): Ámbitos tecnológicos, ámbitos de poder. La transición Bronce Final-Hierro en la Península Ibérica. Actas del Congreso internacional (Madrid, 2004). (http://humanidades.cchs.csic.es/ih/ paginas/arqueometalurgia/Descargas/sem04/s04_gal. pdf [acceso 07-11-2013]).

García de Figuerola, M. (1982): "Nueva estela decorada del tipo II en San Martín de Trevejo (Cáceres)", $Z e$ phyrus, 34-35, pp. 173-180.

Gozalbes, E. (2009): “El Padre César Morán Bardón. La arqueología y la etnografía, de Salamanca a Marruecos", Salamanca. Revista de Estudios, 57, pp. 51-63.

Hardacker, R. (1976): "Las hachas de cubo en la Península Ibérica”, Cuadernos de Prehistoria y Arqueología Castellonense, 3, pp. 151-171.

Harrison, R. J. (1980): "A Late Bronze Age mould from Los Oscos (Prov. Oviedo)”, Madrider Mitteilungen, 21, pp. 131-139.

Herrán, J. I. (2008): Arqueometalurgia de la Edad del Bronce en Castilla y León. Studia Archaeologica, 95. Valladolid.

Levy, J. E. (1982): Social and Religious Organization in Bronze Age Denmark: an Analysis of Ritual Hoard Finds. BAR, Intern. Ser., 124. Oxford: Archaeopress.

López Jiménez, O. (2003): "Dataciones radiocarbónicas en la protohistoria del sudoeste de la Meseta Norte. Consideraciones para un trabajo por hacer", Trabajos de Prehistoria, 60 (2), pp. 131-142.
López Jiménez, O. (2005): "Paisajes y estructura social en la Protohistoria del área sudoccidental de la Meseta Norte”. En Blanco, A.; Cancelo, C. y Esparza, Á.: Bronce Final y Edad del Hierro en la Península Ibérica. Encuentro de Jóvenes Investigadores. Col. Aquilafuente, 86. Salamanca: Univ. Salamanca, pp. 336-355.

Maluquer de Motes, J. (1950): "Estado actual de nuestro conocimiento sobre la prehistoria salmantina (hasta la Edad del Hierro)", Zephyrus, I, pp. 7-21.

Maluquer de Motes, J. (1956): Carta Arqueológica de España: Salamanca. Salamanca: Diput. Provincial.

Maluquer de Motes, J. (1958): Excavaciones arqueológicas en el Cerro del Berrueco. Acta Salmanticensia, 14 (1). Salamanca: Univ. Salamanca.

Martín Benito, J. I. (2010): "Una estela de la Edad del Bronce en Robleda (Salamanca)". En Ciudad Rodrigo: Carnaval del Toro 2010, pp. 339-342.

Martín Mompeán, J. L. (1992): "Nuevas aportaciones al estudio de dos estelas decoradas halladas en la cuenca sur del Duero (Beira Alta, Portugal)", Cuadernos de Prehistoria y Arqueología de la Universidad Autónoma de Madrid, 19, pp. 67-93.

Mohen, J. P. (1978): “Moules en bronze de l'Age du Bronze”, Antiquités Nationales, 10, pp. 23-32.

Mohen, J. P. (1992): Metalurgia prehistórica. Introducción a la paleometalurgia. Barcelona: Masson.

Monteagudo, L. (1977): Die Beile auf der Iberischen Halbinsel. Prähistorische Bronzefunde. Abt. Ix, Band 6 . Munchen: C. H. Beck.

Montero, I.; Fernández Rodríguez, M.; Gómez Tubío, B. y Ontalba, M. a A. (2002): "Espadas y puñales del Bronce Final: el depósito de armas de Puertollano (Ciudad Real)", Gladius, xxiı, pp. 5-28.

Montero, I.; Rovira, S.; Delibes, G.; Fernández Manzano, J.; Fernández Posse, M. a D.; Herrán, J. I.; Martín, C. y Maicas, R. (2003): "High leaded bronze in the Late Bronze Age metallurgy of the Iberian Peninsula". En Archaeometallurgy in Europe. Proceedings, vol. 2. Milán: Associazione Italiana di Metallurgia, pp. 39-46.

Morán, C. (1919): "Noticias arqueológicas de la provincia de Salamanca”, La Basílica Teresiana, año vi, n. ${ }^{\circ}$ 59, pp. 147-155.

Morán, C. (1938): "Colección salmantina de fíbulas", Revista de Guimaräes, 48, pp. 111-136.

Morán, C. (1940): Mapa histórico de la Provincia de Salamanca. Salamanca: Imprenta de Calatrava.

Morán, C. (1941): "Molde salmantino para hachas de talón”. En Martínez Santa-Olalla, J. (ed.): Corona de estudios que la sociedad española de antropología, etnografía y prehistoria dedica a sus mártires. Madrid: Csic, pp. 185-189.

Morán, C. (1942): "Albores de Historia Salmantina, Iv: los metales", Revista de Guimarães, 52 (3-4), pp. 145-154. 
Morán, C. (1945): "Primeras manifestaciones de la cultura salmantina”, Boletín de la Biblioteca de Menéndez Pelayo, xxI, pp. 152-181.

Morán, C. (1946): Reseña histórico artística de la provincia de Salamanca. Salamanca: Univ. Salamanca.

Pericot, L. (1934 [1942]): Historia de España. Gran historia general de los pueblos hispanos 1: Epocas primitiva y romana. Barcelona: Instituto Gallach.

Presedo, F. (1993): "Colección Julio Martínez Santa-Olalla”. En Marcos, A. (coord.): De Gabinete a Museo. Tres siglos de Historia. Madrid: Ministerio de Cultura, pp. 474-483.

Quero, S. (1996): "Cuarenta años de historia del Instituto Arqueológico Municipal”, Estudios de Prehistoria y Arqueología Madrileña, 10, pp. 193-200.

Rauret, A. M. ${ }^{a}$ (1976): La metalurgia del bronce en la Península Ibérica durante la Edad del Hierro. Barcelona: Univ. de Barcelona-Inst. Arqueología y Prehistoria.

Rodrigues, A. V. (1958): "Estela da Idade do Bronze encontrada em Meimão (Penamacor)”, Zephyrus, IX, pp. 225-226.

Ruiz-Gálvez Priego, M. (1995): “Depósitos del Bronce Final: ¿Sagrado o profano? ¿Sagrado y, a la vez, profano?”. En Ruiz-Gálvez, M. (ed.): Ritos de paso y puntos de paso. La Ría de Huelva en el mundo del Bronce Final europeo. Complutum Extra, 5. Madrid, pp. 19-32.

SAnabria, P. J. (2011): "La estela decorada del puerto de Honduras (Cabezuela del Valle, Cáceres).” En VIlaçA, R. (coord.): Estelas e estátuas menires da Pré à Proto-história (Actas IV Jornadas Raianas). Sabugal, pp. 369-388.

Santonja, M. (1997): "Los Tiempos Prehistóricos". En Salinas, M. (coord.) y Martín, J. L. (dir.): Historia de Salamanca. Tomo 1: Prehistoria y Edad Antigua. Salamanca: Centro de Estudios Salmantinos.

Santos, A. T.; Vilaça, R. y Marques, J. N. (2011): "As estelas do Baraçal, Sabugal (Beira interior, Portugal).” En VILAÇA, R. (coord.): Estelas e estátuas menires da Pré à Proto-história (Actas IV Jornadas Raianas). Sabugal, pp. 319-342.

Senna-Martinez, J. C. (2007): “Depósitos versus oficinas de fundidor: problemas contextuales de la arqueometalurgia en Portugal". En Celis, J.; Delibes de Castro, G.; Fernández Manzano, J. y Grau Lobo, L. (eds.): El hallazgo leonés de Valdevimbre y los depósitos del bronce final atlántico en la Península Ibérica. León: Diput. de León, pp. 258-278.

Senna-Martinez, J. C. y Pedro, I. (2000): "Between myth and reality: the foundry area of Senhora da Guia de Baióes and Baióes/Santa Luzia metallurgy", Trabalhos de Arqueologia da EAM, 6, pp. 61-77.

Sierra, J. C. (1978): Sobre la tecnología del Bronce Final en los talleres del Noroeste hispánico. Studia Archaeologica, 47. Valladolid.
Sierra, J. C.; Vázquez, A. J.; De Luis, L. y Ferreira, S. (1984): El depósito del Bronce Final de Samieira. Investigación Arqueoanalitica y Experimental. Boletín Auriense, Anexo 2. Orense.

Silva, A. C. F. (2007) [1986]: A Cultura castreja no Noroeste de Portugal. Paços de Ferreira: C.M. de Paços de Ferreira, Museu Arqueológico de Citânia de Sanfins.

Silva, A. C. F.; Silva, C. T. y Lopes, A. B. (1984): “Depósito de fundidor do final da Idade do Bronze do castro da Senhora da Guia (Baióes, S. Pedro do Sul, Viseu)", Lucerna. (Homenagem a D. Domingos de Pinho Brandão). Porto, pp. 73-109.

Teixeira, C. (1940): "Molde de fundição para machados de bronze de duplo anel", Trabalhos da Sociedade Portuguesa de Antropologia e Etnologia, 9 (1-2), pp. 126-130.

Tylecote, R. F. (1976): A History of Metallurgy. London: The Metals Society.

Tylecote, R. F. (1987): The Early History of metallurgy in Europe. London: Longman.

Valério, P.; Araújo, M. F.; Senna-Martínez, J. C. y Vaz, J. L. (2006): "Caracterização química de produçóes metalúrgicas do castro da Senhora da Guia de Baióes (Bronze Final)", O Arqueólogo Português, 24, serie IV, pp. 289-319.

VÁzquez Seijas, M. (1944): "Curioso molde para fundición de hachas de talón", Boletín de la Comisión Provincial de Monumentos Históricos y Artísticos de Lugo, t. I, n. ${ }^{\text {os }} 10-11$, pp. $298-301$.

VÁzQuez Seijas, M. (1953): "Hachas de bronce de doble anillo", Boletín de la Comisión Provincial de Monumentos Históricos y Artísticos de Lugo, t. v, n. ${ }^{\circ}$ 9, pp. 208-211.

VilaçA, R. (2006): “Depósitos de bronze do território português. Um debate em aberto”, O Arqueólogo Português, serie IV, n. ${ }^{\circ} 24$, pp. 9-150.

VilaçA, R.; Osorio, M. y SAntos, A. T. (2011a): "Nova peça insculturada da região raiana do Sabugal (Beira Interior, Portugal): uma primeira abordagem". En VIlaça, R. (coord.): Estelas e estátuas menires da Pré à Proto-história (Actas IV Jornadas Raianas). Sabugal, pp. 343-367.

VilaçA, R.; Santos, A. T. y Gomes, S. M. (2011b): "As estelas da Pedra da Atalaia (Celorico da Beira, Guarda) no seu contexto geo-arqueológico". En VILAÇA, R. (coord.): Estelas e estátuas menires da Pré à Proto-história (Actas IV Jornadas Raianas). Sabugal, pp. 293-318.

vv. AA. (2009): Portable antiquities and treasures. Annual Report 2007. London: BM.

WyMER, J. J. (1987): “A pair of bronze palstave moulds from Harling”, Norfolk Archaeology, 40, pp. 122-126. 